\title{
Identification and structure characterization of five synthetic opioids: 3,4-methylenedioxy-U-47700, o-methyl-acetylfentanyl, 2-thiophenefentanyl, benzoylfentanyl and benzoylbenzylfentanyl
}

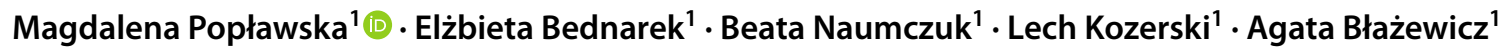

Received: 10 April 2020 / Accepted: 30 May 2020 / Published online: 19 June 2020

(c) The Author(s) 2020

\begin{abstract}
Purpose The number of new synthetic opioids, especially fentanyl analogs, on the illicit market is increasing each year and becoming a disturbing phenomenon. Due to the very high potency, ease of addiction and high risk of overdose with the fatal effect, they pose a serious threat to public health. The ever-changing drug market, lack of reference standards and low doses make this class of new psychoactive substances (NPS) a continual analytical challenge in terms of detection and identification. Structure elucidations of five synthetic opioids are described in this paper.

Methods Unequivocal identifications were performed using liquid chromatography-high resolution tandem mass spectrometry with quadrupole time-of-flight analyzer (LC-QTOF-MS/MS) and nuclear magnetic resonance (NMR) spectroscopy with prior chromatographic purification of the sample in each case.

Results Identified NPS included one non-fentanyl opioid belonging to "U-compounds group"-3,4-methylenedioxy-U-47700 and four fentanyl analogs: $o$-methyl-acetylfentanyl, benzoylfentanyl, 2-thiophenefentanyl and benzoylbenzylfentanyl.

Conclusions Complementary LC-QTOF-MS/MS and NMR techniques enabled the unambiguous identification of new synthetic opioids. To the best of our knowledge, this is the first comprehensive characterization of these five NPS with complete data which are published to facilitate their detection and identification by forensic and clinical laboratories.
\end{abstract}

Keywords Synthetic opioids $\cdot$ Non-fentanyl and fentanyl analogs $\cdot$ Structure identification $\cdot$ New psychoactive substance (NPS) · Liquid chromatography-high resolution tandem mass spectrometry with quadrupole time-of-flight analyzer (LCQTOF-MS/MS) · Nuclear magnetic resonance (NMR) spectroscopy

\section{Introduction}

New psychoactive substances (NPS) available on European drug market pose a public health problem and challenge not only for policymakers but also analysts. By the end of 2018, over 730 NPS have been reported to the European Monitoring Center for Drugs and Drug Addiction (EMCDDA) through the Early Warning System (EWS). As many as 55 NPS were detected for the first time in Europe in 2018 [1]. Among all the groups of substances monitored, the most

Magdalena Popławska

m.poplawska@nil.gov.pl

$\triangle$ Elżbieta Bednarek

e.bednarek@nil.gov.pl

1 National Medicines Institute, 30/34 Chełmska Street, 00-725 Warsaw, Poland numerous are still synthetic cannabinoids, followed by derivatives of cathinone and phenylethylamine. A disturbing phenomenon is the appearance of substances from the group of opioids, especially fentanyl derivatives, and the fact that the number of new analogs identified is increasing each year. By the end of 2018, 49 new opioids were detected on the European drug market, including 34 fentanyl derivatives, as many as 10 fentanyl derivatives of which were first reported in 2018. They are unregistered derivatives of active pharmaceutical substance-fentanyl, used in authorized medicinal products. Considering their very high potency, ease of addiction and high risk of overdose with the fatal effect (due to respiratory depression), they pose a serious threat to public health $[2,3]$. Other synthetic opioids, which are non-fentanyl derivatives, belong mainly to the group of the $N$-substituted benzamides and acetamides colloquially called "U-compounds" or the group of $N$-substituted cyclohexylmethylbenzamides known as the "AH-compounds" [4]. Majority of 
these fentanyl and non-fentanyl analogs were synthesized and patented as potential non-addictive analgesics. Although they have been discarded on the next stage of drug development (mainly due to unsatisfying results of toxicity tests, side effects or potency), they are easily available on the illicit drug market. Novel synthetic opioids are distributed in various forms: powders, tablets, herbal mixtures and liquids.

Over the past 10 years, in National Medicines Institute (NMI), Poland, we have examined seven thousand samples of designer drugs in which about two hundred NPS have been detected by liquid chromatography-electrospray ionization-quadrupole time-of flight mass spectrometry (LC-ESI-QTOF-MS) and nuclear magnetic resonance (NMR) spectroscopy. Thirty-two of them were new on the EU market and were reported to the EWS-EMCDDA. Among 13 synthetic opioids which were identified in our laboratory, as many as 8 have been reported to the EWSEMCDDA for the first time (Table 1).

In Polish legislation, the problem of psychoactive substances is regulated by the Act of July 29, 2005 on counteracting drug addiction, which has been amended several times in recent years, first of all to control more NPS. In 2018, the amendment of the Act introduced a generic character for four NPS groups containing the basic core of the molecule and defined possible substituents, covering most substances from derivatives of 2-phenylethylamine, cathinone, synthetic cannabinoids (cannabinomimetics), and fentanyl derivatives. According to the last amendment of 2019, the fifth open group of benzodiazepines has been added.

A lot of new synthetic opioids have been identified and characterized recently [5-7], including a fentanyl derivative: furanylfentanyl [8] and a non-fentanyl: U-47700 [9, 10]. The identification of novel opioids is a continual analytical challenge due to their variety, low dose needed to cause desired effects, the lack of analytical data available for these substances and the lack of reference standards.

Here we describe the identification of five synthetic opioids detected in four illegal products (sample A, B, C and D) investigated in NMI laboratory. Analyses based on complementary methods LC-QTOF-MS/MS and NMR spectroscopy allowed elucidating their structures. Sample A contained a single compound belonging to "U-compounds group" identified as 3,4-methylenedioxy-U-47700 (compound 1), in sample B two fentanyl analogs were detected: $o$-methyl-acetylfentanyl (compound 2) and benzoylfentanyl (compound 3). Herbal sample $\mathrm{C}$ was enhanced with

toring Centre for Drugs and Drug Addiction (EWS-EMCDDA) and the years since they are controlled in Poland

Table 1 Years of the first identification of the synthetic opioid in samples by National Medicines Institute (NMI) in Poland, the years of the first reports to the Early Warning System-the European Moni-

\begin{tabular}{|c|c|c|c|c|}
\hline Year & Substance & Chemical name & EMCDDA & Controlled in Poland since \\
\hline \multirow[t]{3}{*}{2014} & Butyrfentanyl (BF) & $\begin{array}{l}N \text {-Phenyl- } N \text {-[1-(2-phenylethyl)piperidin-4-yl] } \\
\text { butanamide }\end{array}$ & $2014^{\mathrm{a}}$ & 2015 \\
\hline & 4-Fluorobutyrfentanyl (4F-BF) & $\begin{array}{l}N \text {-(4-Fluorophenyl)- } N \text {-[(1-(2-phenylethyl) } \\
\text { piperidin-4-yl)]butanamide }\end{array}$ & $2014^{\mathrm{a}}$ & 2015 \\
\hline & Furanylfentanyl (FU-F) & $\begin{array}{l}N \text {-Phenyl- } N \text {-[1-(2-phenylethyl)piperidin-4-yl] } \\
\text { furan-2-carboxamide }\end{array}$ & 2015 & 2018 \\
\hline \multirow[t]{6}{*}{2017} & U-47700 & $\begin{array}{l}\text { 3,4-Dichloro- } N \text {-[2-(dimethylamino) } \\
\text { cyclohexyl]- } N \text {-methylbenzamide }\end{array}$ & 2015 & 2018 \\
\hline & Cyclopropylfentanyl & $\begin{array}{l}N \text {-Phenyl- } N \text {-[1-(2-phenylethyl)piperidin-4-yl] } \\
\text { cyclopropanecarboxamide }\end{array}$ & 2017 & 2018 \\
\hline & 2-Thiophenefentanyl & $\begin{array}{l}N \text {-Phenyl- } N \text {-[1-(2-phenylethyl)piperidin-4-yl] } \\
\text { thiophene-2-carboxamide }\end{array}$ & $2017^{\mathrm{a}}$ & 2018 (generic law) \\
\hline & Benzylfentanyl & $\begin{array}{l}N \text {-(1-Benzylpiperidin-4-yl)- } N \text {-phenylpropan- } \\
\text { amide }\end{array}$ & $2017^{\mathrm{a}}$ & 2018 \\
\hline & Acetylbenzylfentanyl ( $N$-benzyl-acetylfentanyl) & $N$-(1-Benzylpiperidin-4-yl)- $N$-phenylacetamide & $2017^{\mathrm{a}}$ & 2018 (generic law) \\
\hline & $\begin{array}{l}\text { Benzoylbenzylfentanyl ( } N \text {-benzyl-benzoylfen- } \\
\text { tanyl) }\end{array}$ & $\begin{array}{l}N \text {-(1-Benzylpiperidin-4-yl)- } N \text {-phenylbenza- } \\
\text { mide }\end{array}$ & $2017^{\mathrm{a}}$ & 2018 (generic law) \\
\hline \multirow[t]{4}{*}{2018} & 4-Fluoro-isobutyrfentanyl (4F-iBF) & $\begin{array}{l}N \text {-(4-Fluorophenyl)-2-methyl- } N \text {-[1-(2-phenyle- } \\
\text { thyl)piperidin-4-yl]propanamide }\end{array}$ & 2016 & 2018 \\
\hline & Benzoylfentanyl & $\begin{array}{l}N \text {-Phenyl- } N \text {-[1-(2-phenylethyl)piperidin-4-yl] } \\
\text { benzamide }\end{array}$ & 2017 & 2018 (generic law) \\
\hline & $\begin{array}{l}o \text {-Methyl-acetylfentanyl (2-methyl-acetylfen- } \\
\text { tanyl) }\end{array}$ & $\begin{array}{l}N \text {-(2-Methylphenyl)- } N \text {-[1-(2-phenylethyl) } \\
\text { piperidin-4-yl]acetamide }\end{array}$ & $2018^{\mathrm{a}}$ & 2018 (generic law) \\
\hline & $\begin{array}{l}\text { 3,4-Methylenedioxy-U-47700 (3,4-MDO-U- } \\
\text { 47700) }\end{array}$ & $\begin{array}{l}N \text {-[2-(Dimethylamino)cyclohexyl]- } N \text {-methyl- } \\
\text { 1,3-benzodioxole-5-carboxamide }\end{array}$ & $2018^{\mathrm{a}}$ & Not controlled \\
\hline
\end{tabular}

${ }^{\text {a }}$ Reported for the first time to EWS-EMCDDA by NMI, Poland 
2-thiophenefentanyl (compound 4) and sample D contained, among several fentanyl analogs, one unknown compound identified as benzoylbenzylfentanyl (compound 5).

\section{Materials and methods}

\section{Materials and reagents}

Samples were collected directly from the users by NMI in Warsaw in 2017 and 2018 as a part of the research project. The pilot testing of psychoactive substances obtained directly from users of "designer drugs" in Poland was implemented within the framework of tasks defined in the National Health Program. Three samples consisted of white powders (samples A, B, D) and one sample was in a form of herbal material (sample C). A reference spectrum of fentanyl was extracted from the data obtained for the original medicinal product Fentanyl WZF from Polfa Warszawa S.A. (Warsaw, Poland).

Methanol and acetonitrile, both of purity suitable for LC-MS, were purchased from Merck Millipore (LiChrosolv; Darmstadt, Germany); formic acid from Honeywell (Metropolis, IL, USA); acetonitrile Chromasolv ${ }^{\mathrm{TM}}$ from Honeywell [high-performance liquid chromatography (HPLC) grade]; dimethyl sulfoxide (DMSO) pure p.a. from POCH SA (Gliwice, Poland); $85 \%$ formic acid p.a. from Chempur (Piekary Śląskie, Poland); methanol- $d_{4}$ [methyl$d_{3}$ alcohol- $d, 99.8$ atom $\% \mathrm{D}$, containing $0.03 \%(\mathrm{v} / \mathrm{v})$ tetramethylsilane (TMS)] $\left(\mathrm{CD}_{3} \mathrm{OD}\right)$ from Armar Isotopes (Dottingen, Switzerland). Doubly distilled water additionally purified in the Nanopure Diamond UV Deionization System from Barnstead (Dubuque, IA, USA) was used throughout.

\section{Sample preparation}

For LC-QTOF-MS/MS analysis, ca. $0.5 \mathrm{mg}$ of powder or ca. $5 \mathrm{mg}$ of herbal mixture was dissolved or extracted with a 1:1:1 (v/v/v) mixture of water/methanol/acetonitrile, with the assistance of ultrasonication for $10 \mathrm{~min}$, and afterwards filtered by Whatman $0.2 \mu \mathrm{m}$ pore size polytetrafluoroethylene filter media (GE Healthcare, Chicago, IL, USA). If necessary, the filtrate was further diluted to a suitable concentration.

For NMR analysis, several milligrams of powder (samples $\mathrm{A}, \mathrm{D}$ ) were dissolved in $0.7 \mathrm{~mL}$ of $\mathrm{CD}_{3} \mathrm{OD}$ and ca. $30 \mathrm{mg}$ of herbal mixture (sample C) was extracted in $1.5 \mathrm{~mL}$ of $\mathrm{CD}_{3} \mathrm{OD}$. Several milligrams of powder (sample B) were dissolved in $1.5 \mathrm{~mL}$ of DMSO and purified using HPLC method. Fraction at retention time 13.4 min (compound 2) and $16.3 \mathrm{~min}$ (compound $\mathbf{3}$ ) was collected, lyophilized and next dissolved in $0.7 \mathrm{~mL}$ of $\mathrm{CD}_{3} \mathrm{OD}$. The solutions were transferred to $5 \mathrm{~mm}$ NMR tube.

\section{Instruments and methods}

\section{High-performance liquid chromatography-quadrupole time-of-flight tandem mass spectrometry}

Identifications of new compounds were performed by means of a high-resolution tandem mass spectrometer with timeof-flight analyzer micrOTOF-QII from Bruker Daltonik (Bremen, Germany) coupled to high-performance liquid chromatography Ultimate 3000 system from Dionex (a part of Thermo Fisher Scientific, Waltham, MA, USA) applying a standard screening method which is used in the laboratory. Chromatographic separations were carried out on Hypersil GOLD C18 analytical column $(100 \times 2.1 \mathrm{~mm}$ i.d., $3 \mu \mathrm{m}$ particle size; Thermo Fisher Scientific) with a guard column Hypersil GOLD $(10 \times 2.1 \mathrm{~mm}$ i.d., $3 \mu \mathrm{m}$ particle size; Thermo Fisher Scientific) at $25{ }^{\circ} \mathrm{C}$. Linear gradient elution using solvent A consisting of water/acetonitrile/formic acid $(90 / 10 / 0.1, \mathrm{v} / \mathrm{v} / \mathrm{v})$ and solvent B consisting of methanol/acetonitrile/formic acid $(90 / 10 / 0.1, \mathrm{v} / \mathrm{v} / \mathrm{v})$ was applied with the flow rate set at $0.15 \mathrm{~mL} \mathrm{~min}^{-1}$ and the following program was used: $0-2 \mathrm{~min}, 10 \% \mathrm{~B} ; 2-7 \mathrm{~min}, 10-90 \% \mathrm{~B}$; 7-9 min, 90\% B ; 9-12 min, 90-10\% B ; $12-14$ min, 10\%B. MS settings were as follows: ESI, positive ion mode; capillary voltage, $4500 \mathrm{~V}$; end plate offset, $-500 \mathrm{~V}$; dry gas flow rate, $8.0 \mathrm{~L}$ $\min ^{-1}$; dry heater, $180{ }^{\circ} \mathrm{C}$; MS data, full scan mode (from $\mathrm{m} / \mathrm{z} 50$ to 1500 ). High mass accuracies were ensured by a calibration of TOF analyzer using a solution of sodium formate prior to each sample. Collision energy was linearly ramped as a function of $\mathrm{m} / \mathrm{z}$ ratio in the fragmentation experiments. For values from $m / z 200$ to 400 , the voltage gradient linearly increased from 20 to $25 \mathrm{eV}$, for values from $\mathrm{m} / z 400$ to 800 , it increased from 25 to $35 \mathrm{eV}$ and for values from $\mathrm{m} / \mathrm{z}$ 800 to 1500 , it held at $35 \mathrm{eV}$. Product ions were obtained by the collision induced dissociation.

\section{HPLC purification for NMR experiments}

Purification of sample B was performed on HPLC system from Shimadzu USA Manufacturing Inc. (Canby, OR, USA) consisting of a low pressure gradient flow LC-20AT pump, a DGU-20A on line solvent degasser, a photodiode array detector SPD-M20A, an SIL-10AF sample injector and an FRC-10A fraction collector. The data were monitored using Shimadzu LabSolution system. Separations were carried out on Bionacom Velocity C18 LPH HPLC column $(150 \times 10 \mathrm{~mm}$ i.d., $3 \mu \mathrm{m}$ particle size; Genore Chromatography, Nagłowice, Poland) using $0.1 \%$ formic acid as an aqueous solvent (A) and acetonitrile as an organic solvent (B), in the following gradient: $0-10 \mathrm{~min}, 20-50 \% \mathrm{~B}$; $10-15 \mathrm{~min}, 50-80 \% \mathrm{~B}$. Flow rate of the mobile phase was set at $3 \mathrm{~mL} \mathrm{~min}{ }^{-1}$. The course of the chromatography was 
monitored using ultraviolet detection at a wavelength of $254 \mathrm{~nm}$ and peaks of interest were collected by the fraction collector.

\section{NMR spectroscopy}

The NMR spectra were recorded at $298 \mathrm{~K}$ on Varian VNMRS-500 spectrometer (Varian, Inc., Palo Alto, CA, USA) operated at 499.8 and $125.7 \mathrm{MHz}$ for ${ }^{1} \mathrm{H}$ and ${ }^{13} \mathrm{C}$, respectively. The spectrometer was equipped with an inverse $\left.{ }^{1} \mathrm{H}_{2}{ }^{31} \mathrm{P}_{-}{ }^{15} \mathrm{~N}\right\}$ the $5 \mathrm{~mm} \mathrm{Z}$-SPEC Nalorac IDG 500-5HT probe with an actively shielded z-gradient coil. The high power ${ }^{1} \mathrm{H}$ and ${ }^{13} \mathrm{C} \pi / 2$ pulses were 7.6 and $11.6 \mu \mathrm{s}$, respectively. The NMR experiments were run using the standard Varian software.

The ${ }^{1} \mathrm{H}$ NMR spectra and the ${ }^{1} \mathrm{H}$ dimension in 2D heteronuclear spectra were referenced to the internal reference of TMS. The $1 \mathrm{D}^{13} \mathrm{C}\left\{{ }^{1} \mathrm{H}\right\}$ spectra and ${ }^{13} \mathrm{C}$ dimension in $2 \mathrm{D}$ heteronuclear spectra were referenced to the solvent $\left(\mathrm{CD}_{3} \mathrm{OD}\right.$, $\delta_{\mathrm{c}}=49.0 \mathrm{ppm}$ ), which was treated as a secondary standard.

A standard single-pulse experiment was used to acquire the ${ }^{1} \mathrm{H}$ spectrum using an $8000 \mathrm{~Hz}$ spectral window, $30^{\circ}$ pulse width, an acquisition time of $4 \mathrm{~s}$, relaxation delay of $2 \mathrm{~s}$, and 64,000 complex data points.

Gradient-selected correlation spectroscopy (COSY): spectral widths, $6000 \mathrm{~Hz}$ in both dimensions; 1024 complex points in $t_{2}, 512$ increments in $t_{1} ; 1-4$ scans per increment; relaxation delay, $1 \mathrm{~s}$; sine-bell squared apodization functions used in processing.

The $1 \mathrm{D}{ }^{13} \mathrm{C}$ NMR spectra were run using a spectral range of $32,000 \mathrm{~Hz}, 30^{\circ}$ pulse width, an acquisition time of $1 \mathrm{~s}$, a relaxation delay of $1 \mathrm{~s}$, and by collecting 32,000 complex data points.

The phase sensitive adiabatic heteronuclear single quantum coherence $\left({ }^{1} \mathrm{H}\left\{{ }^{13} \mathrm{C}\right\} \mathrm{HSQC}\right)$ : spectral widths, $6000 \mathrm{~Hz}$ in $\mathrm{F} 2$ and $21,300 \mathrm{~Hz}$ in $\mathrm{F} 1 ; 1024$ complex points in $t_{2}, 512$ complex points in $t_{1} ; 4$ scans per increment; relaxation delay of $1 \mathrm{~s} ;{ }^{1} J(\mathrm{C}, \mathrm{H})=146 \mathrm{~Hz}$. The data were linearly predicted to $1 \mathrm{~K}$ and zero filled to $4 \mathrm{~K}$ complex data points in $\mathrm{F} 1$ and processed using cosine window function in both dimensions prior to Fourier transformation.

The phase sensitive gradient-selected adiabatic heteronuclear multiple bond correlation $\left({ }^{1} \mathrm{H}\left\{{ }^{13} \mathrm{C}\right\} \mathrm{HMBC}\right)$ : spectral widths, $6000 \mathrm{~Hz}$ in F2 and 25,100 Hz in F1; 1024 complex points in $t_{2}, 512$ complex points in $t_{1} ; 4-16$ scans per increment; relaxation delay of $1 \mathrm{~s} ;{ }^{n} J_{(\mathrm{C}, \mathrm{H})}=8 \mathrm{~Hz}$. The data were processed using sine-bell square multiplication in F2 and Gaussian window function in F1 dimensions prior to Fourier transformation.

The signals in the ${ }^{1} \mathrm{H}$ and ${ }^{13} \mathrm{C}$ NMR spectra of studied compounds were assigned to the proton and carbon atoms in the appropriate structural fragments with the aid of the proton-proton coupling pattern and the proton-proton and proton-carbon correlations obtained from ${ }^{1} \mathrm{H}\left\{{ }^{1} \mathrm{H}\right\} \mathrm{COSY}$, ${ }^{1} \mathrm{H}\left\{{ }^{13} \mathrm{C}\right\} \mathrm{HSQC}$ and ${ }^{1} \mathrm{H}\left\{{ }^{13} \mathrm{C}\right\} \mathrm{HMBC}$ experiments. The presence of oxygen, nitrogen and sulfur ions in structures of studied compounds and the molecular formulae were determined on the basis of QTOF-MS results.

\section{Results}

LC-MS/MS chromatogram obtained for sample A displayed a single peak at $6.9 \mathrm{~min}$ corresponding to compound $\mathbf{1}$, the structure of which was further investigated on the basis of mass spectrometric data. Two main peaks at $8.4 \mathrm{~min}$ for compound $\mathbf{2}$ and at 8.9 min for compound $\mathbf{3}$ were detected in sample B. A peak at the retention time of $8.7 \mathrm{~min}$ was recorded for the extract of sample C. It corresponded to compound 4 and its structure elucidation is described below. Sample D was a mixture of several compounds. Two main compounds were identified as $N$-benzylfentanyl at $7.8 \mathrm{~min}$ and 1-benzyl-4-propionyloxypiperidine at $6.7 \mathrm{~min}$. There were two other less intense peaks. The first one at $7.4 \mathrm{~min}$ was derived from acetylbenzylfentanyl, and the last one at 8.2 min was unknown compound $\mathbf{5}$, the structure of which was characterized using QTOF-MS/MS data.

Except for the LC-MS/MS spectrum of compound 3 and some ${ }^{1} \mathrm{H}$ NMR spectra without assignments, all presented analytical data had not been previously described in any scientific articles, reports, EMCDDA notifications or databases at the time points of our identification (Table 1).

Accurately measured masses, exact (theoretical) masses, the error, relative intensities and elemental compositions for precursor ions and product ions are displayed in Table 2. Proposed fragmentations of identified compounds are presented in Figs. 1, 2, 3, 4, 5, 6. The mass accuracies for precursor ions in MS spectra were largely below $5 \mathrm{ppm}$, although for some product ions of very low intensity the mass error was higher.

\section{Identification of compound 1: 3,4-methylenedioxy-U-47700}

\section{LC-QTOF-MS/MS results}

The protonated molecular ion $[\mathrm{M}+\mathrm{H}]^{+}$at $m / z 305.1848$ with predicted chemical formula $\mathrm{C}_{17} \mathrm{H}_{25} \mathrm{~N}_{2} \mathrm{O}_{3}{ }^{+}$(error $3.7 \mathrm{ppm}$ ) was recorded. The most intense product ion at $\mathrm{m} / \mathrm{z}, 260.1286$ $\left(\mathrm{C}_{15} \mathrm{H}_{18} \mathrm{NO}_{3}{ }^{+}\right)$was formed by the cleavage of dimethylamine. Subsequent product ions in the MS/MS spectrum (Fig. 1) derived from the cleavage of $\mathrm{C}-\mathrm{N}$ bonds on the nitrogen from the amide bond. The amide bond breakage formed the product ion at $\mathrm{m} / \mathrm{z} 149.0234$, whereas the cleavage of dimethylaminocyclohexane moiety resulted in two product ions corresponding to dimethylaminocyclohexane 
Table 2 Cumulative data of electrospray ionizationquadrupole time-of-flighttandem mass spectra obtained for investigated new synthetic opioids

\begin{tabular}{|c|c|c|c|c|c|c|}
\hline Compound name & $\begin{array}{l}\text { Precursor ion }{ }^{\mathrm{a}} \\
{[\mathrm{M}+\mathrm{H}]^{+}} \\
\text {Product ions } \\
(\mathrm{m} / \mathrm{z})\end{array}$ & Chemical formula & $\begin{array}{l}\text { Theoretical } \\
\text { value } \\
(\mathrm{m} / \mathrm{z})\end{array}$ & $\begin{array}{l}\text { Error } \\
(\mathrm{mDa})\end{array}$ & $\begin{array}{l}\text { Error } \\
(\mathrm{ppm})\end{array}$ & $\begin{array}{l}\text { Relative } \\
\text { intensity } \\
(\%)\end{array}$ \\
\hline $\begin{array}{l}\text { 3,4-Methylenedioxy-U } \\
-47700\end{array}$ & $305.1848^{\mathrm{a}}$ & $\mathrm{C}_{17} \mathrm{H}_{25} \mathrm{~N}_{2} \mathrm{O}_{3}$ & 305.1860 & 1.1 & 3.7 & 2.2 \\
\hline \multirow[t]{7}{*}{ (compound 1) } & 260.1286 & $\mathrm{C}_{15} \mathrm{H}_{18} \mathrm{NO}_{3}$ & 260.1281 & -0.5 & -1.9 & 100 \\
\hline & 180.0656 & $\mathrm{C}_{9} \mathrm{H}_{10} \mathrm{NO}_{3}$ & 180.0655 & -0.1 & -0.3 & 6.4 \\
\hline & 162.0546 & $\mathrm{C}_{9} \mathrm{H}_{8} \mathrm{NO}_{2}$ & 162.0550 & 0.3 & 2.1 & 0.1 \\
\hline & 149.0234 & $\mathrm{C}_{8} \mathrm{H}_{5} \mathrm{O}_{3}$ & 149.0233 & -0.1 & -0.6 & 8.5 \\
\hline & 126.1274 & $\mathrm{C}_{8} \mathrm{H}_{16} \mathrm{~N}$ & 126.1277 & 0.3 & 2.3 & 0.4 \\
\hline & 123.0448 & $\mathrm{C}_{7} \mathrm{H}_{7} \mathrm{O}_{2}$ & 123.0441 & -0.7 & -5.7 & 0.5 \\
\hline & 81.0699 & $\mathrm{C}_{6} \mathrm{H}_{9}$ & 81.0699 & -0.1 & -0.9 & 0.1 \\
\hline \multirow{13}{*}{$\begin{array}{l}o \text {-Methyl-acetylfentanyl } \\
\text { (compound 2) }\end{array}$} & $337.2265^{\mathrm{a}}$ & $\mathrm{C}_{22} \mathrm{H}_{29} \mathrm{~N}_{2} \mathrm{O}$ & 337.2274 & 0.9 & 2.8 & 72.2 \\
\hline & 295.2139 & $\mathrm{C}_{20} \mathrm{H}_{27} \mathrm{~N}_{2}$ & 295.2169 & 3 & 10 & 0.2 \\
\hline & 245.1652 & $\mathrm{C}_{15} \mathrm{H}_{21} \mathrm{~N}_{2} \mathrm{O}$ & 245.1648 & -0.3 & -1.4 & 0.1 \\
\hline & 216.1380 & $\mathrm{C}_{14} \mathrm{H}_{18} \mathrm{NO}$ & 216.1383 & 0.3 & 1.2 & 5.2 \\
\hline & 188.1434 & $\mathrm{C}_{13} \mathrm{H}_{18} \mathrm{~N}$ & 188.1434 & -0.1 & -0.3 & 100 \\
\hline & 186.1268 & $\mathrm{C}_{13} \mathrm{H}_{16} \mathrm{~N}$ & 186.1277 & 1 & 5.2 & 0.6 \\
\hline & 176.1057 & $\mathrm{C}_{11} \mathrm{H}_{14} \mathrm{NO}$ & 176.1070 & 1.3 & 7.2 & 0.3 \\
\hline & 160.1112 & $\mathrm{C}_{11} \mathrm{H}_{14} \mathrm{~N}$ & 160.1121 & 0.9 & 5.4 & 0.3 \\
\hline & 150.0897 & $\mathrm{C}_{9} \mathrm{H}_{12} \mathrm{NO}$ & 150.0913 & 1.6 & 10.6 & 0.4 \\
\hline & 146.0960 & $\mathrm{C}_{10} \mathrm{H}_{12} \mathrm{~N}$ & 146.0964 & 0.4 & 2.8 & 1.5 \\
\hline & 134.0963 & $\mathrm{C}_{9} \mathrm{H}_{12} \mathrm{~N}$ & 134.0964 & 0.2 & 1.1 & 1.5 \\
\hline & 105.0702 & $\mathrm{C}_{8} \mathrm{H}_{9}$ & 105.0699 & -0.4 & -3.4 & 5.4 \\
\hline & 84.0811 & $\mathrm{C}_{5} \mathrm{H}_{10} \mathrm{~N}$ & 84.0808 & -0.3 & -3.8 & 0.1 \\
\hline \multirow{11}{*}{$\begin{array}{l}\text { Benzoylfentanyl } \\
\text { (compound } \mathbf{3} \text { ) }\end{array}$} & $385.2253^{\mathrm{a}}$ & $\mathrm{C}_{26} \mathrm{H}_{29} \mathrm{~N}_{2} \mathrm{O}$ & 385.2274 & 2.1 & 5.5 & 28.1 \\
\hline & 279.1814 & $\mathrm{C}_{19} \mathrm{H}_{23} \mathrm{~N}_{2}$ & 279.1856 & 4.2 & 15.1 & 0.1 \\
\hline & 264.1385 & $\mathrm{C}_{18} \mathrm{H}_{18} \mathrm{NO}$ & 264.1383 & -0.3 & -1 & 0.8 \\
\hline & 238.1197 & $\mathrm{C}_{16} \mathrm{H}_{16} \mathrm{NO}$ & 238.1226 & 2.9 & 12.3 & 0.3 \\
\hline & 198.0900 & $\mathrm{C}_{13} \mathrm{H}_{12} \mathrm{NO}$ & 198.0913 & 1.3 & 6.8 & 0.6 \\
\hline & 188.1436 & $\mathrm{C}_{13} \mathrm{H}_{18} \mathrm{~N}$ & 188.1434 & -0.3 & -1.4 & 100 \\
\hline & 160.1127 & $\mathrm{C}_{11} \mathrm{H}_{14} \mathrm{~N}$ & 160.1121 & -0.6 & -4 & 0.5 \\
\hline & 146.0962 & $\mathrm{C}_{10} \mathrm{H}_{12} \mathrm{~N}$ & 146.0964 & 0.3 & 1.8 & 0.9 \\
\hline & 134.0971 & $\mathrm{C}_{9} \mathrm{H}_{12} \mathrm{~N}$ & 134.0964 & -0.7 & -4.9 & 0.8 \\
\hline & 105.0340 & $\mathrm{C}_{7} \mathrm{H}_{5} \mathrm{O}$ & 105.0335 & -0.5 & -4.6 & 11.1 \\
\hline & 84.0817 & $\mathrm{C}_{5} \mathrm{H}_{10} \mathrm{~N}$ & 84.0808 & -0.9 & -11 & 0.07 \\
\hline \multirow{11}{*}{$\begin{array}{l}\text { 2-Thiophenefentanyl } \\
\text { (compound 4) }\end{array}$} & $391.1831^{\mathrm{a}}$ & $\mathrm{C}_{24} \mathrm{H}_{27} \mathrm{~N}_{2} \mathrm{OS}$ & 391.1839 & 0.8 & 2 & 30.7 \\
\hline & 270.0944 & $\mathrm{C}_{16} \mathrm{H}_{16} \mathrm{NOS}$ & 270.0947 & 0.3 & 1.2 & 0.9 \\
\hline & 244.0783 & $\mathrm{C}_{14} \mathrm{H}_{14} \mathrm{NOS}$ & 244.0791 & 0.8 & 3.2 & 0.2 \\
\hline & 204.0468 & $\mathrm{C}_{11} \mathrm{H}_{10} \mathrm{NOS}$ & 204.0478 & 0.9 & 4.7 & 0.8 \\
\hline & 188.1439 & $\mathrm{C}_{13} \mathrm{H}_{18} \mathrm{~N}$ & 188.1434 & -0.5 & -2.8 & 100 \\
\hline & 160.1106 & $\mathrm{C}_{11} \mathrm{H}_{14} \mathrm{~N}$ & 160.1121 & 1.5 & 9.2 & 0.3 \\
\hline & 146.0963 & $\mathrm{C}_{10} \mathrm{H}_{12} \mathrm{~N}$ & 146.0964 & 0.1 & 0.5 & 0.7 \\
\hline & 134.0966 & $\mathrm{C}_{9} \mathrm{H}_{12} \mathrm{~N}$ & 134.0964 & -0.2 & -1.4 & 0.9 \\
\hline & 110.9903 & $\mathrm{C}_{5} \mathrm{H}_{3} \mathrm{OS}$ & 110.9899 & -0.4 & -3.7 & 4.8 \\
\hline & 105.0702 & $\mathrm{C}_{8} \mathrm{H}_{9}$ & 105.0699 & -0.3 & -2.7 & 5.1 \\
\hline & 84.0796 & $\mathrm{C}_{5} \mathrm{H}_{10} \mathrm{~N}$ & 84.0808 & 1.2 & 14 & 0.1 \\
\hline \multirow{4}{*}{$\begin{array}{l}\text { Benzoylbenzylfentanyl } \\
\text { (compound 5) }\end{array}$} & $371.2105^{\mathrm{a}}$ & $\mathrm{C}_{25} \mathrm{H}_{27} \mathrm{~N}_{2} \mathrm{O}$ & 371.2118 & 1.3 & 3.4 & 29.6 \\
\hline & 264.1388 & $\mathrm{C}_{18} \mathrm{H}_{18} \mathrm{NO}$ & 264.1383 & -0.5 & -2 & 0.5 \\
\hline & 198.0903 & $\mathrm{C}_{13} \mathrm{H}_{12} \mathrm{NO}$ & 198.0913 & 1 & 5.1 & 0.8 \\
\hline & 188.1066 & $\mathrm{C}_{12} \mathrm{H}_{14} \mathrm{NO}$ & 188.1070 & 0.4 & 2 & 1.1 \\
\hline
\end{tabular}


Table 2 (continued)

\begin{tabular}{|c|c|c|c|c|c|c|}
\hline \multirow[t]{7}{*}{ Compound name } & $\begin{array}{l}\text { Precursor ion }{ }^{\mathrm{a}} \\
{[\mathrm{M}+\mathrm{H}]^{+}} \\
\text {Product ions } \\
(\mathrm{m} / \mathrm{z})\end{array}$ & Chemical formula & $\begin{array}{l}\text { Theoretical } \\
\text { value } \\
(\mathrm{m} / \mathrm{z})\end{array}$ & $\begin{array}{l}\text { Error } \\
(\mathrm{mDa})\end{array}$ & $\begin{array}{l}\text { Error } \\
(\mathrm{ppm})\end{array}$ & $\begin{array}{l}\text { Relative } \\
\text { intensity } \\
(\%)\end{array}$ \\
\hline & 174.1281 & $\mathrm{C}_{12} \mathrm{H}_{16} \mathrm{~N}$ & 174.1277 & -0.4 & -2.4 & 100 \\
\hline & 146.0959 & $\mathrm{C}_{10} \mathrm{H}_{12} \mathrm{~N}$ & 146.0964 & 0.5 & 3.8 & 0.6 \\
\hline & 120.0806 & $\mathrm{C}_{8} \mathrm{H}_{10} \mathrm{~N}$ & 120.0808 & 0.2 & 1.6 & 0.4 \\
\hline & 105.0337 & $\mathrm{C}_{7} \mathrm{H}_{5} \mathrm{O}$ & 105.0335 & -0.2 & -2.2 & 14.3 \\
\hline & 91.0538 & $\mathrm{C}_{7} \mathrm{H}_{7}$ & 91.0542 & 0.4 & 4.4 & 10.3 \\
\hline & 82.0652 & $\mathrm{C}_{5} \mathrm{H}_{8} \mathrm{~N}$ & 82.0651 & -0.1 & -1.3 & 0.2 \\
\hline
\end{tabular}

Fig. 1 Product ion spectra by liquid chromatography-electrospray ionization-quadrupole time-of-flight tandem mass spectrometry (LC-ESI-QTOFMS/MS) for 3,4-methylenedioxy-U-47700 (compound 1) with assigned fragmentation pattern; auto-scaled view (upper) and zoomed view (lower)

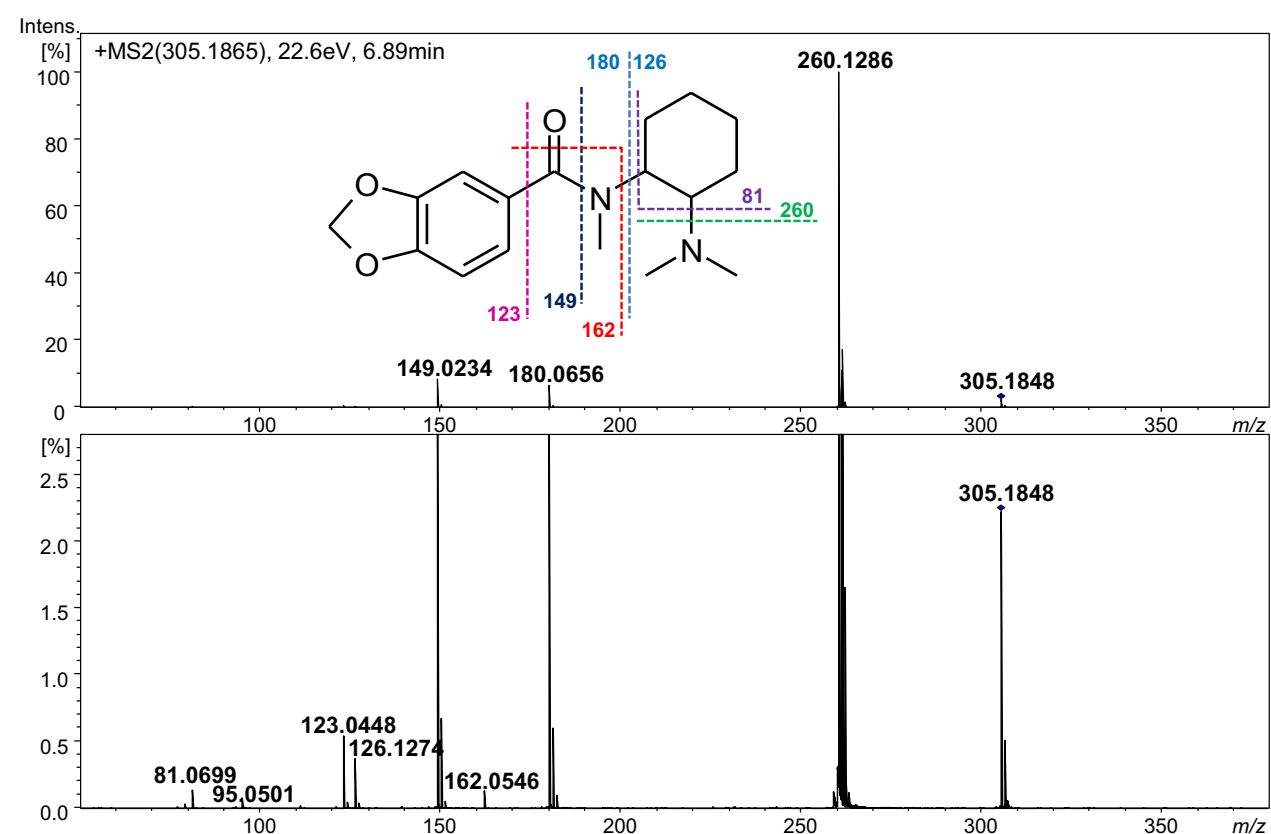

at $m / z, 126.1274$ and $N$-methyl-1,3-benzodioxole-5-carboxamide fragment at $\mathrm{m} / \mathrm{z} 180.0656$. Two minor signals at $\mathrm{m} / \mathrm{z}$ 81.0699 and 123.0448 are characteristic of rings which are present in the molecule: cyclohexyl ring and methylenedioxyphenyl ring, respectively. The structure of compound $\mathbf{1}$ was further elucidated by NMR spectra.

\section{NMR spectroscopy}

The NMR data for compound $\mathbf{1}$ are collected in Table 3. In the ${ }^{1} \mathrm{H}$ NMR spectrum of compound $\mathbf{1}$, there were signals belonging to 24 protons (three singlets of $\mathrm{CH}_{3}$ groups, seven multiplets in the range of 1.4-4.7 ppm, one signal at $6.02 \mathrm{ppm}$ of $\mathrm{CH}_{2}$ group and three signals of aromatic protons). The ${ }^{13} \mathrm{C}$ NMR spectrum consisted of seventeen signals, thirteen of which on the basis of the ${ }^{1} \mathrm{H}\left\{{ }^{13} \mathrm{C}\right\} \mathrm{HSQC}$ spectrum were assigned to $\mathrm{CH}_{3}$ (three signals), $\mathrm{CH}_{2}$ (five signals) and $\mathrm{CH}$ (two signals in aliphatic and three in aromatic part of spectrum) groups. The other four signals belong to quaternary carbon atoms.
The occurrence in ${ }^{1} \mathrm{H}$ NMR spectrum of the aliphatic spin-spin coupling pattern in the range of $1.4-4.7 \mathrm{ppm}$ belonging to ten protons and simultaneously the presence in ${ }^{13} \mathrm{C}$ NMR spectrum of carbon atom signals belonging to four $\mathrm{CH}_{2}$ groups and two $\mathrm{CH}$ groups confirmed the presence of the double-substituted cyclohexyl ring.

The ${ }^{1} \mathrm{H}$ and ${ }^{13} \mathrm{C}$ chemical shifts of signals of three $\mathrm{CH}_{3}$ groups as well as of two $\mathrm{CH}$ groups of the double-substituted cyclohexyl ring may suggest that these groups are connected to the heteroatom, e.g., nitrogen atom. The connection of $\mathrm{CH}_{3}$ groups to the nitrogen atoms which are simultaneously connected to a cyclohexyl ring was confirmed by the occurrence of strong cross-peaks through three bonds in ${ }^{1} \mathrm{H}\left\{{ }^{13} \mathrm{C}\right\} \mathrm{HMBC}$ spectrum: H10-C11, H17-C12, H12-C17 and $\mathrm{H} 12-\mathrm{C} 18$.

The occurrence of the signals of three aromatic protons in the ${ }^{1} \mathrm{H}$ NMR spectrum as well as the presence of the three signals of $\mathrm{CH}$ group and three signals of quaternary carbon atom in the aromatic part of the ${ }^{13} \mathrm{C}$ NMR spectrum indicated the presence of double substituted phenyl ring. 
Additionally, the ${ }^{13} \mathrm{C}$ chemical shifts (about $150 \mathrm{ppm}$ ) of quaternary carbon atoms $\mathrm{C} 1 \mathrm{a}$ and $\mathrm{C} 3 \mathrm{a}$ of this ring suggested that these carbon atoms were connected to the oxygen atom. The presence of strong cross-peaks in the ${ }^{1} \mathrm{H}\left\{{ }^{13} \mathrm{C}\right\}$ HMBC spectrum: $\mathrm{H} 2-\mathrm{C} 3 \mathrm{a}$ and $\mathrm{H} 2-\mathrm{C} 1$ a confirmed that $\mathrm{CH}_{2}$ group is connected to the double substituted phenyl group. Moreover, the ${ }^{1} \mathrm{H}$ and ${ }^{13} \mathrm{C}$ chemical shifts of the $\mathrm{CH}_{2}$ group (6.02/103.1 ppm) indicated that this group is connected to phenyl ring via oxygen atom. Based on above information, the presence of the 1,3-benzodioxole moiety could be confirmed in the structure of the tested compound.

Moreover, in the ${ }^{13} \mathrm{C}$ NMR spectrum, there was a signal of quaternary carbon atom located at $175.1 \mathrm{ppm}(\mathrm{C} 8)$ which could be attributed to the amide group. The complex proton spectral pattern around C11-C12 bond did not allow the assessment of cis/trans geometry along this bond, although, considering the bulky substituents on both carbon atoms, trans geometry should be favored.

Finally, the structure of compound $\mathbf{1}$ was determined as $N$-[2-(dimethylamino)cyclohexyl]- $N$-methyl-1,3-benzodioxole-5-carboxamide, so-called 3,4-methylenedioxy-U-47700 or 3,4-MDO-U-47700.

\section{Identification of compound 2: o-methyl-acetylfentanyl}

\section{LC-QTOF-MS/MS results}

The mass spectrum of the analyte with the precursor ion $[\mathrm{M}+\mathrm{H}]^{+}$at $m / z 337.2265$, corresponding to the protonated molecule $\mathrm{C}_{22} \mathrm{H}_{29} \mathrm{~N}_{2} \mathrm{O}^{+}$, was similar to MS data obtained for fentanyl. Furthermore, almost all product ions, both main fragments (at $\mathrm{m} / \mathrm{z}, 188.1434$ originated from
$N$-phenylethylpiperidine, at $\mathrm{m} / \mathrm{z} 105.0702$ corresponding to phenylethyl moiety and at $m / z 216.1380$ formed by cleavage of $\mathrm{C}-\mathrm{N}$ bonds in piperidine ring) and those of relative intensity below $2 \%$, could be found in the MS/MS spectrum of fentanyl. However, the cleavage of an amide bond formed distinctive fragments for fentanyl precursor ion at $m / z 281.2018$ corresponding to $\mathrm{C}_{19} \mathrm{H}_{25} \mathrm{~N}_{2}{ }^{+}$and for $o$-methyl-acetylfentanyl at $\mathrm{m} / \mathrm{z}, 295.2139$ which matches with elemental composition $\mathrm{C}_{20} \mathrm{H}_{27} \mathrm{~N}_{2}^{+}$. Characteristic difference of $14 \mathrm{Da}$ and confirmed presence of $N$-phenylethylpiperidine indicated that the methyl group is attached to $\mathrm{N}$-phenyl ring. The product ion spectrum of compound $\mathbf{2}$ is depicted in Fig. 2. Comparison of fentanyl and compound 2 fragmentation spectra is shown in Fig. 3. However, to determine the position of the methyl group at the phenyl ring, the NMR experiment was necessary to be conducted.

\section{NMR spectroscopy}

The NMR data for compound $\mathbf{2}$ are collected in Table 4. In the ${ }^{1} \mathrm{H}$ NMR spectrum, there were: two singlets of $\mathrm{CH}_{3}$ groups, an AA'BB' aliphatic spin system $\left(-\mathrm{CH}_{2}-\mathrm{CH}_{2}-\right.$ moiety), nine multiplets in the range of $1.4-4.5 \mathrm{ppm}$ and signals of nine aromatic protons. The ${ }^{13} \mathrm{C}$ NMR spectrum consisted of twenty signals belonging to carbon atoms of $\mathrm{CH}_{3}$ (two signals), $\mathrm{CH}_{2}$ (six signals) and $\mathrm{CH}$ groups (one signal in aliphatic and seven in aromatic part of spectrum) as well as to the four of quaternary carbon atom.

The spin-spin coupling pattern in the range of 1.4-4.5 ppm belonging to nine protons was assigned to para substituted piperidine ring on the basis of the ${ }^{1} \mathrm{H}\left\{{ }^{1} \mathrm{H}\right\} \mathrm{COSY}$ and ${ }^{1} \mathrm{H}\left\{{ }^{13} \mathrm{C}\right\} \mathrm{HSQC}$ spectra (the protons are connected with five carbon atoms of four $\mathrm{CH}_{2}$ groups and one $\mathrm{CH}$ group).

Table 3 Experimental 1 dimensional (D) and 2D nuclear magnetic resonance (NMR) spectroscopic data of compound $\mathbf{1}$ in $\mathrm{CD}_{3} \mathrm{OD}$

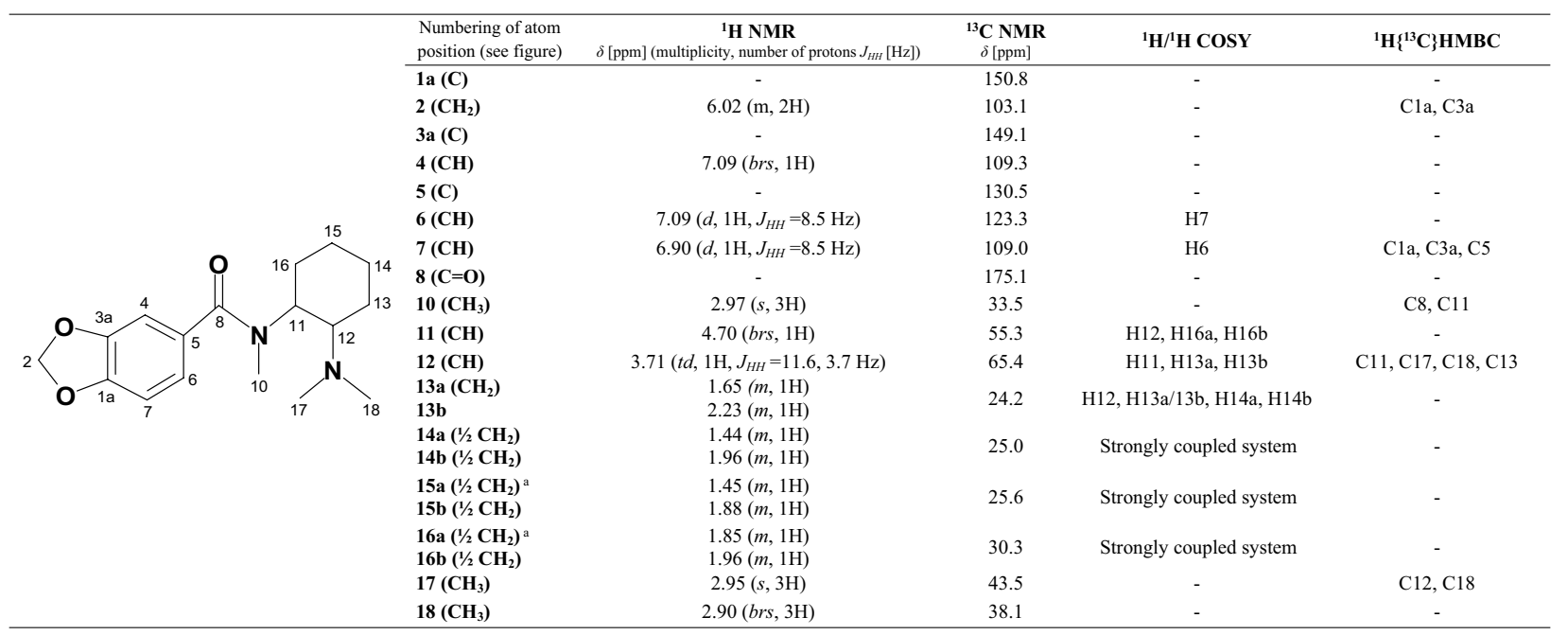

brs broad singlet, COSY correlation spectroscopy, $\delta$ chemical shift [ppm], $d$ doublet, $H M B C$ heteronuclear multiple bond correlation, $J_{H H}$ proton-proton coupling constant [Hz], $m$ multiplet, $s$ singlet, $t d$ triplet of doublets

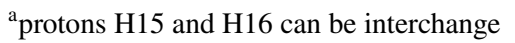


Fig. 2 Product ion spectra by LC-ESI-QTOF-MS/MS for $o$-methyl-acetylfentanyl (compound 2) with assigned fragmentation pattern; autoscaled view (upper) and zoomed view (lower)

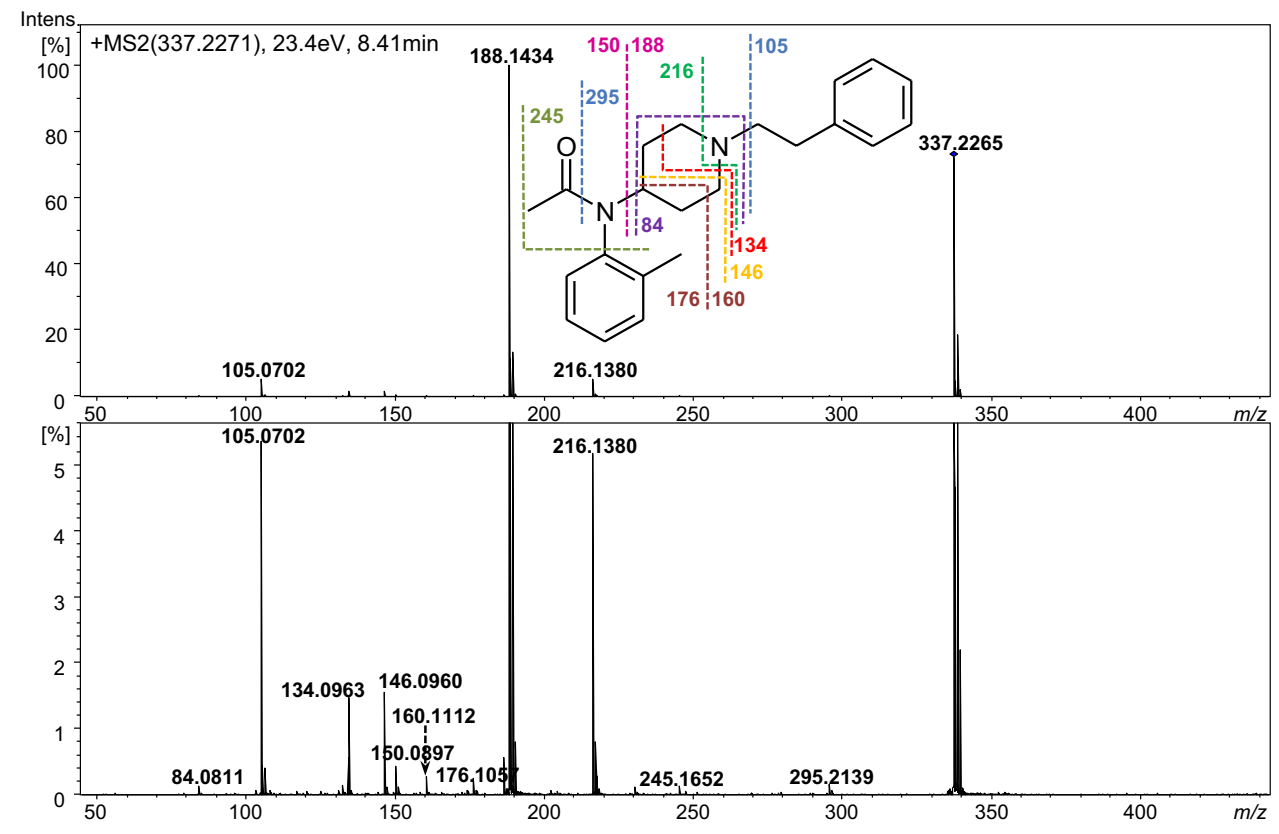

The symmetrical para substitution of piperidine ring was confirmed by the identical chemical shifts of carbon atoms $\mathrm{C} 2$ and $\mathrm{C} 6$. However, the unsymmetrical remote environment, flanking the $3-\mathrm{CH}_{2}$ and $5-\mathrm{CH}_{2}$ groups, adjacent to a substitution center, may induce observed geminal nonequivalence in proton and carbon spectra (see Table 4) of these groups. The ${ }^{1} \mathrm{H}$ and ${ }^{13} \mathrm{C}$ chemical shifts of the $\mathrm{CH}$ group of piperidine ring $(4.51 / 54.8 \mathrm{ppm})$ indicated that this group is connected with heteroatom e.g., nitrogen atom.
The occurrence of the coupling system of nine aromatic protons in the ${ }^{1} \mathrm{H}$ NMR spectrum as well as the presence of the seven signals of $\mathrm{CH}$ group and three signals of quaternary carbon atom in the aromatic part of the ${ }^{13} \mathrm{C} \mathrm{NMR}$ spectrum indicated the presence of one phenyl group and one substituted phenyl group. The substituent was a $\mathrm{CH}_{3}$ group, attached in ortho-position, confirmed by the longrange proton-carbon correlations obtained from ${ }^{1} \mathrm{H}\left\{{ }^{13} \mathrm{C}\right\}$ HMBC spectrum; the $\mathrm{CH}_{3}$ group located at $2.27 \mathrm{ppm}$
Fig. 3 Product ion spectra by LC-ESI-QTOF-MS/MS for fentanyl and $o$-methyl-acetylfentanyl (compound 2) with assigned distinctive fragments; auto-scaled views of: fentanyl (a), o-methyl-acetylfentanyl (b); zoomed views of: fentanyl (c), $o$-methyl-acetylfentanyl (d)

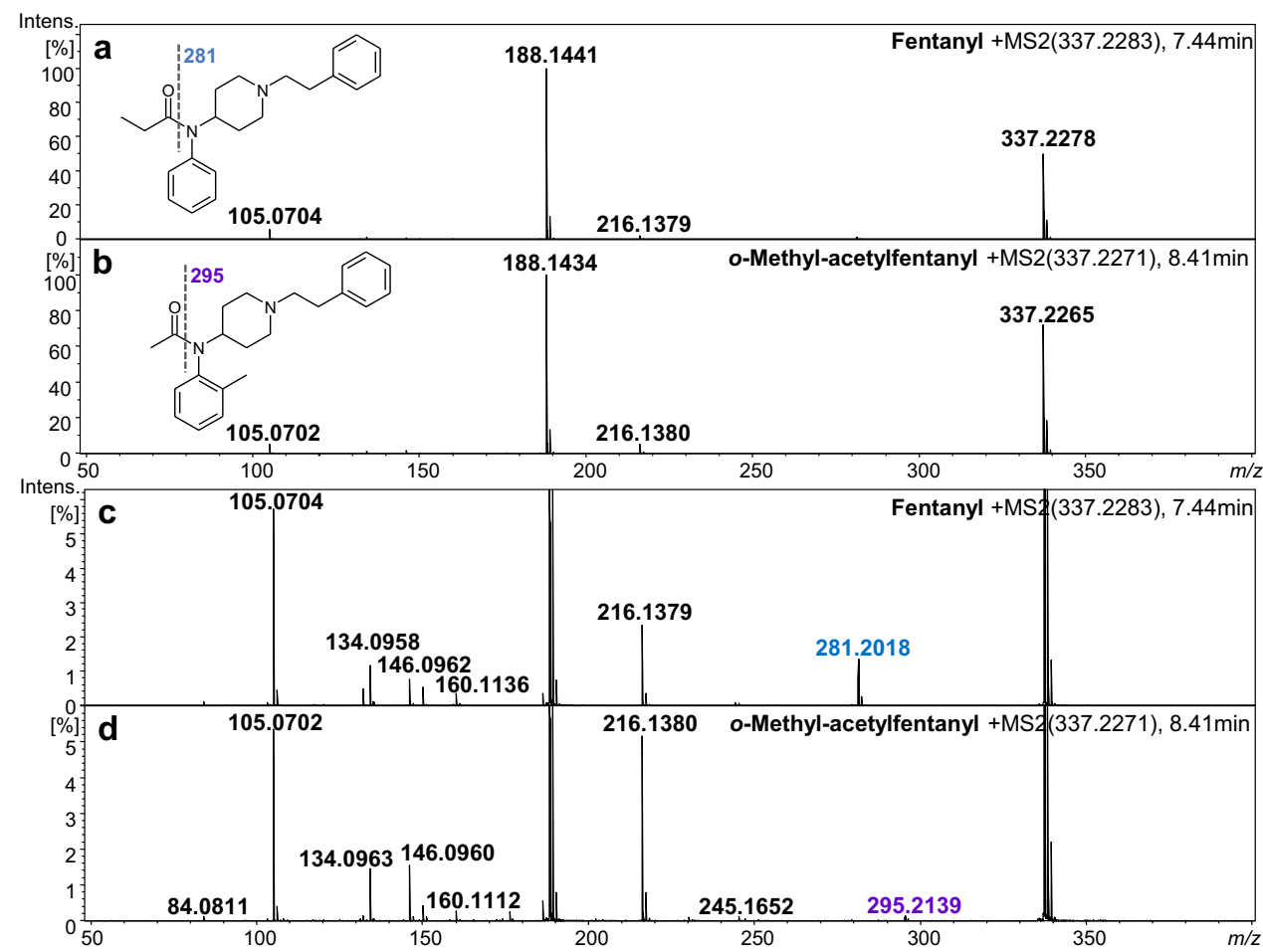


Table 4 Experimental 1D and 2D NMR spectroscopic data of compound 2 in $\mathrm{CD}_{3} \mathrm{OD}$

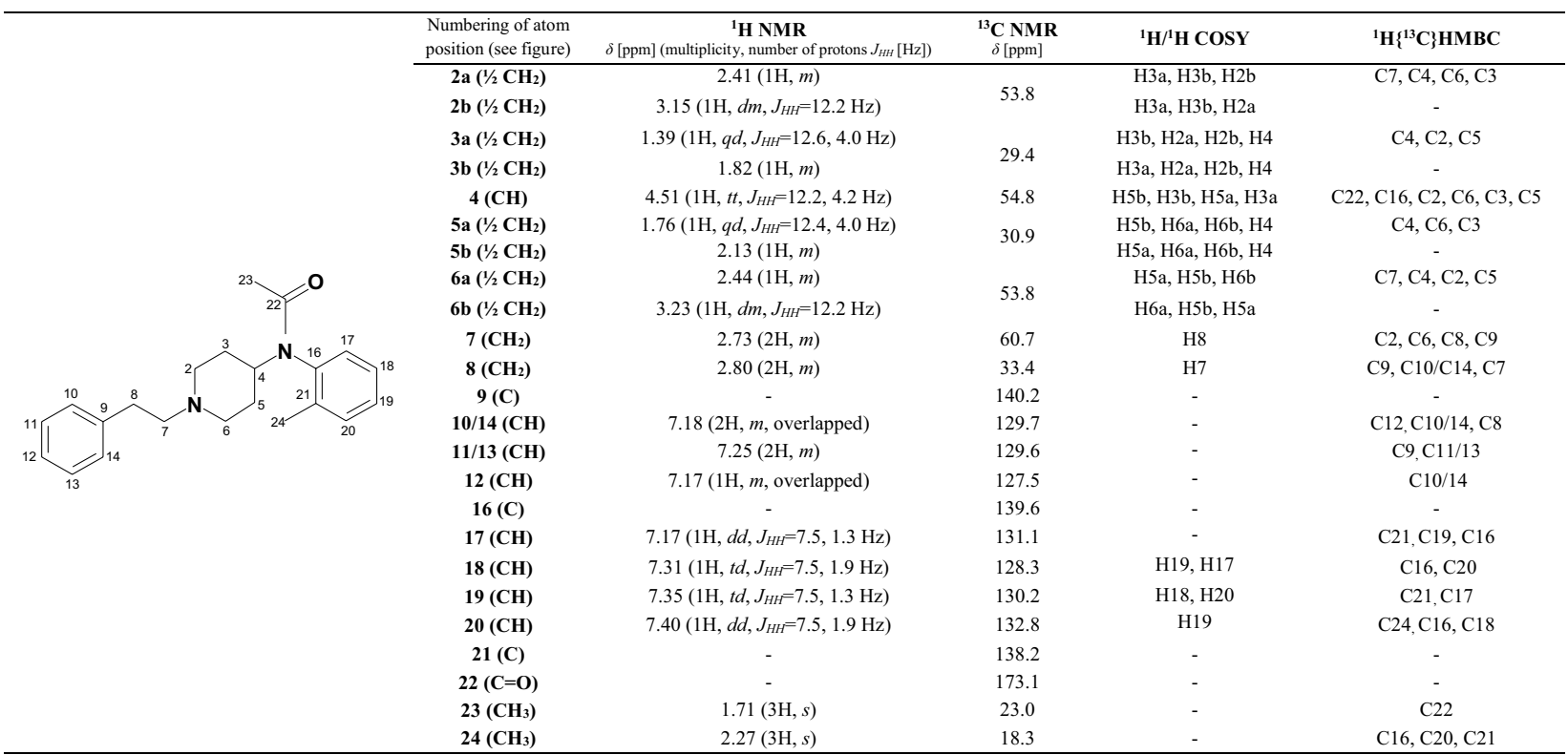

$d d$ doublet of doublets, $d m$ doublet of multiplets, $q d$ quartet of doublets, $t t$ triplet of triplets (for other abbreviations, see Table 3 )

(H24) gave the strong cross-peaks to two signals of quaternary carbon atoms at $138.2 \mathrm{ppm}(\mathrm{C} 21)$ and $139.6 \mathrm{ppm}$ (C16) and to one carbon atom of $\mathrm{CH}$ group at $132.8 \mathrm{ppm}$ (C20).

The NMR data also confirmed the presence of an ethylene group $-\mathrm{CH}_{2}-\mathrm{CH}_{2}-$. That group is connected to the phenyl ring as well as to piperidine ring via nitrogen atom as evidenced by occurring strong cross-peaks in the ${ }^{1} \mathrm{H}\left\{{ }^{13} \mathrm{C}\right\} \mathrm{HMBC}$ spectrum: $\mathrm{H} 10 / 14-\mathrm{C} 8$, H8-C $10 / 14$, H8-C9, H2a-C7, H6a-C7, H7-C2, and H7-C6. The ${ }^{1} \mathrm{H}$ and ${ }^{13} \mathrm{C}$ chemical shifts of the ethylene group $(2.80 / 33.4 \mathrm{ppm}$ and $2.73 / 60.7 \mathrm{ppm}$ ) also confirmed that this group is connected to piperidine ring via nitrogen atom.

Moreover, in ${ }^{13} \mathrm{C}$ NMR spectrum, there was a signal of quaternary carbon atom located at $173.1 \mathrm{ppm}$ (C22) and signal of $\mathrm{CH}_{3}$ group at $23.0 \mathrm{ppm}(\mathrm{C} 23)$ which could be attributed to the acetamide group. The piperidine ring as well as ortho-substituted phenyl group were connected to the nitrogen atom of acetamide group as evidenced by occurring strong cross-peaks in the ${ }^{1} \mathrm{H}\left\{{ }^{13} \mathrm{C}\right\} \mathrm{HMBC}$ spectrum: H4-C22 and H4-C16.

Finally, compound 2 was determined as $N$-(2methylphenyl)- $N$-[1-(2-phenylethyl)piperidin-4-yl] acetamide (ortho-methyl-acetylfentanyl).

\section{Identification of compound 3: benzoylfentanyl}

\section{LC-OTOF-MS/MS results}

The LC-QTOF-MS/MS data of compound 3 displayed the protonated monoisotopic ion $[\mathrm{M}+\mathrm{H}]^{+}$at $\mathrm{m} / \mathrm{z} 385.2253$
$\left(\mathrm{C}_{26} \mathrm{H}_{29} \mathrm{~N}_{2} \mathrm{O}^{+}\right.$, error $\left.5.5 \mathrm{ppm}\right)$. MS/MS experiment formed two main product ions (Fig. 4). The most intense ion at $\mathrm{m} / z 188.1436$ corresponded to $\mathrm{N}$-phenylethylpiperidine moiety. The exact mass of the second product ion at $\mathrm{m} / \mathrm{z}$ 105.0340 determined the most possible formula $\mathrm{C}_{7} \mathrm{H}_{5} \mathrm{O}^{+}$ and indicated that this product ion derived rather from the benzoyl group than from phenylethyl moiety that is also included in fentanyl or $o$-methyl-acetylfentanyl (Figs. 2, 3 ). Phenylethyl product ion of the latter two drugs gave a theoretical value at $\mathrm{m} / \mathrm{z} 105.0699$, but its low intensity with the limited resolution of mass spectrometer did not allow observing it as a completely separated ion. Apart from the benzoyl product ion, the cleavage of amide bond resulted in the fragment at $\mathrm{m} / \mathrm{z} 279.1814$ corresponding to $N$-phenyl-1-(2-phenylethyl)piperidin-4-amine. An ion at $\mathrm{m} / \mathrm{z} 198.0900$ corresponded to $\mathrm{N}$-phenylbenzamide substructure. Formation of several minor fragments at $\mathrm{m} / \mathrm{z}$ 134.0971, 146.0962, 160.1127, 264.1385 and 238.1197 was a consequence of cleavages of piperidine ring bonds. The structure of compound $\mathbf{3}$ was further revealed by NMR spectra.

\section{NMR spectroscopy}

The NMR data for compound $\mathbf{3}$ are collected in Table 5 . In the ${ }^{1} \mathrm{H}$ NMR spectrum there were signals belonging to thirteen aliphatic and fifteen aromatic protons. In the ${ }^{13} \mathrm{C}$ NMR spectrum there were eighteen signals, from which four can be assigned to the carbon atoms of the $\mathrm{CH}_{2}$ groups and ten to the $\mathrm{CH}$ groups (one signal in aliphatic and nine in 
Fig. 4 Product ion spectra by LC-ESI-QTOF-MS/MS for benzoylfentanyl (compound 3) with assigned fragmentation pattern; auto-scaled view (upper) and zoomed view (lower)
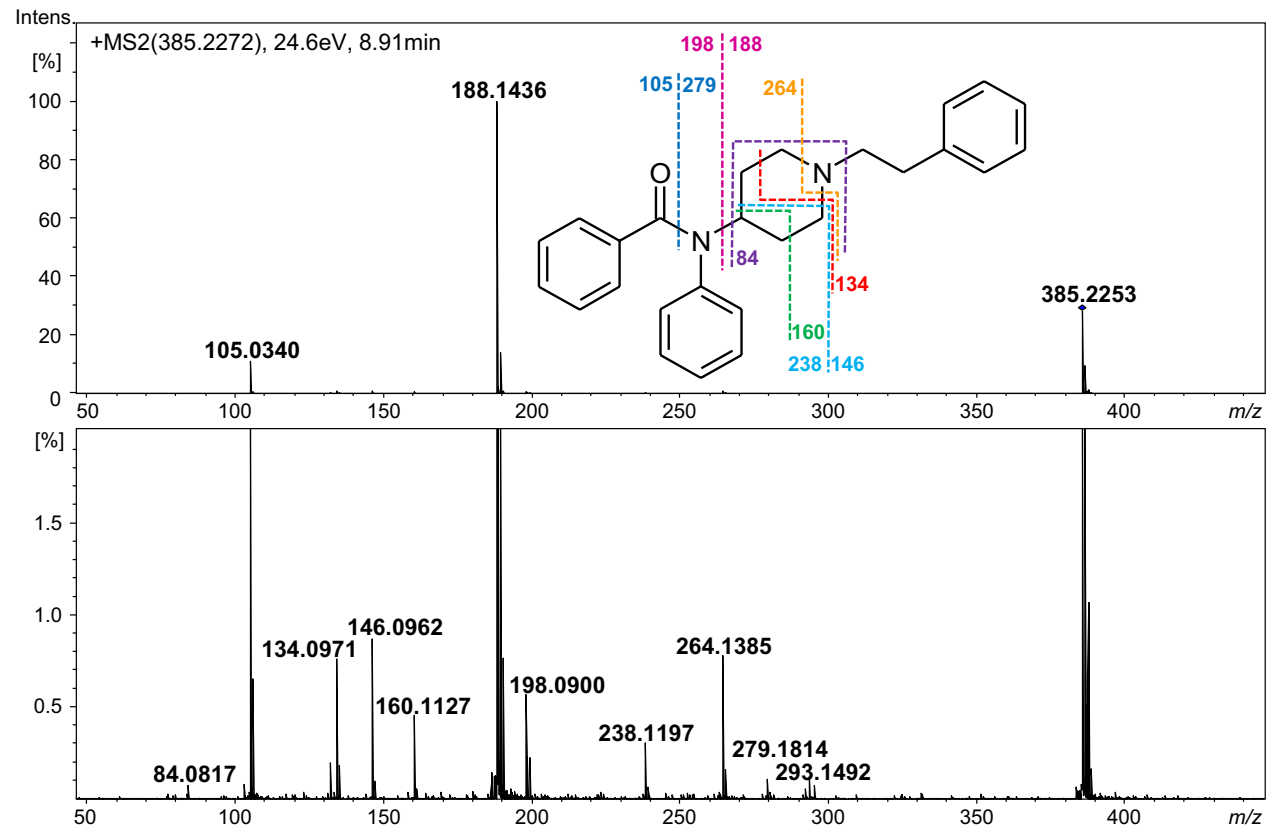

aromatic part of spectrum). The other four signals belonged to quaternary carbon atoms.

The five multiples of nine protons in the range of 1.7-4.7 ppm in the ${ }^{1} \mathrm{H}$ NMR spectrum were assigned to para substituted piperidine ring. In this compound in contrast to compound 2 , equivalent protons at positions $2 \mathrm{a}$ and $6 \mathrm{a}, 2 \mathrm{~b}$ and $6 \mathrm{~b}, 3 \mathrm{a}$ and $5 \mathrm{a}$, and $3 \mathrm{~b}$ and $5 \mathrm{~b}$ were observed. Also in the ${ }^{13} \mathrm{C}$ NMR spectrum only two carbon atom signals connected with those protons were observed pointing to equivalent carbon atoms at positions 2 and 6, and 3 and 5. Additionally, the ${ }^{1} \mathrm{H}$ and ${ }^{13} \mathrm{C}$ chemical shifts of the $\mathrm{CH}$ group of piperidine $(4.72 / 55.0 \mathrm{ppm})$ indicated that this group is connected with nitrogen atom like for compounds 2 .

The occurrence of the coupling system of fifteen aromatic protons in the ${ }^{1} \mathrm{H}$ NMR spectrum as well as the presence of the nine signals of $\mathrm{CH}$ group and three signals of quaternary carbon atom in the aromatic part of the ${ }^{13} \mathrm{C}$ NMR spectrum indicated the presence of three phenyl groups.

Table 5 Experimental 1D and 2D NMR spectroscopic data of compound 3 in $\mathrm{CD}_{3} \mathrm{OD}$

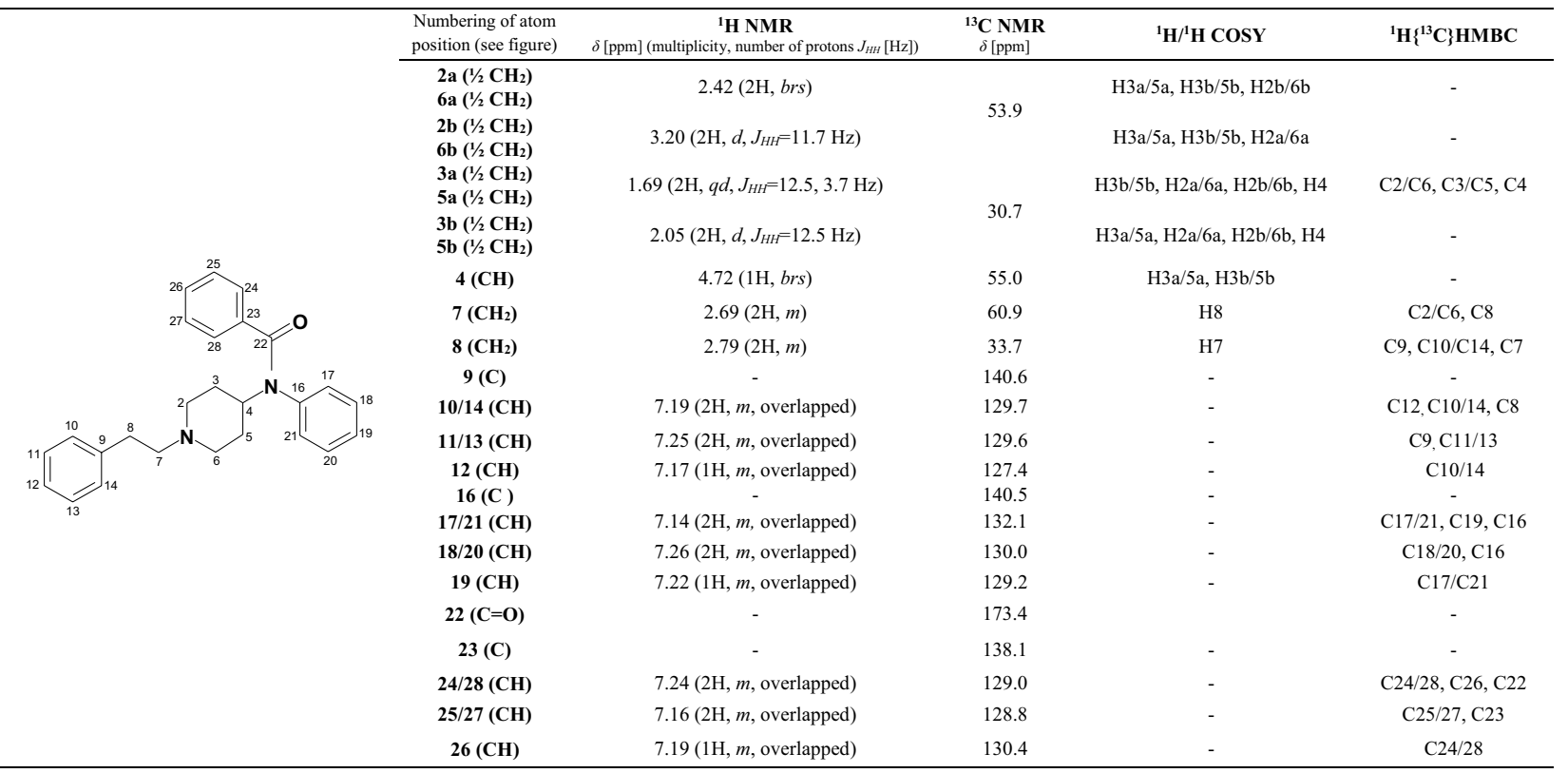

(for abbreviations, see Tables 3 and 4) 
Fig. 5 Product ion spectra by LC-ESI-QTOF-MS/MS for 2-thiophenefentanyl (compound 4) with assigned fragmentation pattern; auto-scaled view (upper) and zoomed view (lower)
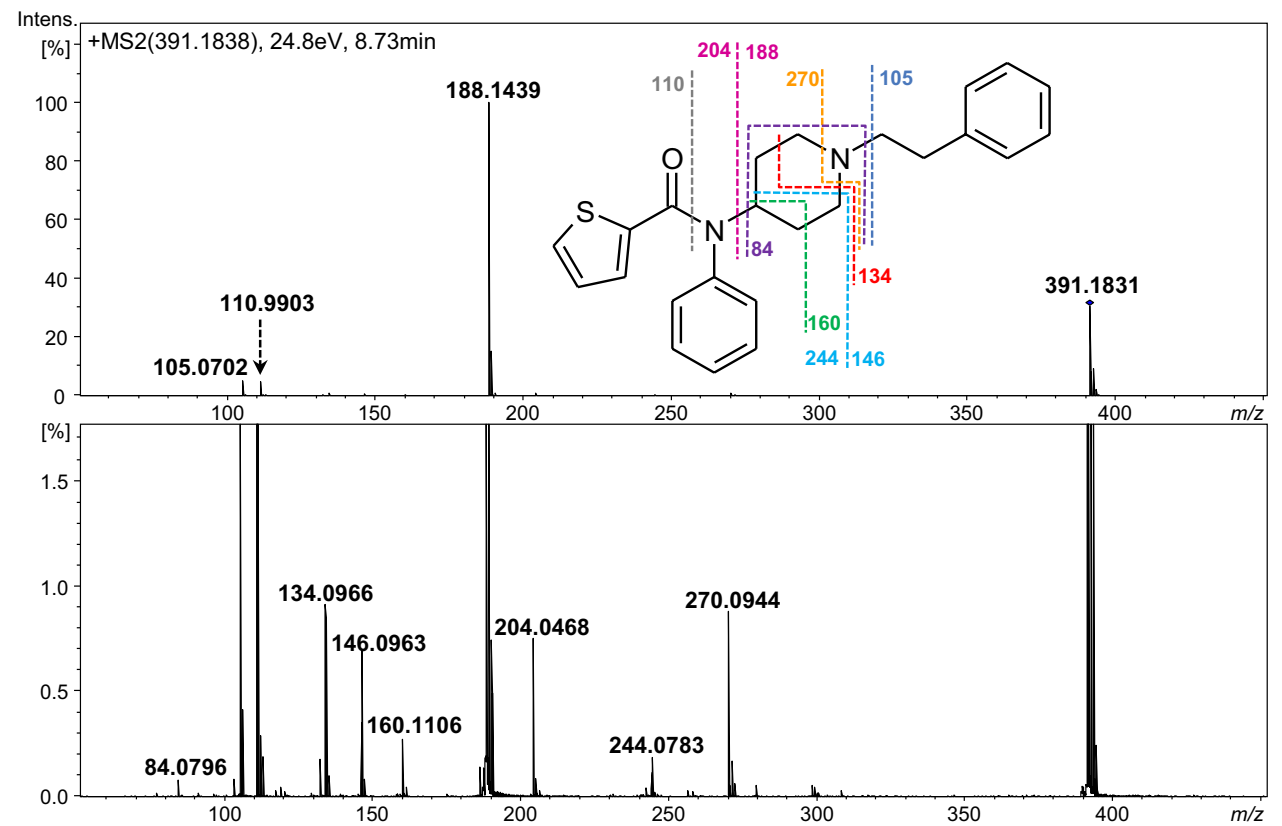

Like in compound 2 , an ethylene group $-\mathrm{CH}_{2}-\mathrm{CH}_{2}-$ is connected to the one of phenyl group as well as to piperidine ring via nitrogen atom.

Moreover, in ${ }^{13} \mathrm{C}$ NMR spectrum there was signal of quaternary carbon atom located at $173.4 \mathrm{ppm}$ (C22) which could be attributed to the amide group. The second phenyl group was attached directly to carbonyl atom as evidenced by occurring a strong cross-peak in the ${ }^{1} \mathrm{H}\left\{{ }^{13} \mathrm{C}\right\} \mathrm{HMBC}$ spectrum: H24/28-C22. The piperidine ring as well as the next phenyl group was connected to the nitrogen atom of amide group.

Finally, the structure of compound $\mathbf{3}$ was determined as $N$-phenyl- $N$-[1-(2-phenylethyl)piperidin-4-yl]benzamide, so-called benzoylfentanyl or phenylfentanyl.

\section{Identification of compound 4: 2-thiophenefentanyl}

\section{LC-QTOF-MS/MS results}

The LC-QTOF-MS/MS data of compound 4 displayed the protonated molecular ion $[\mathrm{M}+\mathrm{H}]^{+}$at $m / z 391.1831$ with the isotope pattern characteristic to a compound containing one sulphur atom in the molecule and suggested formula $\mathrm{C}_{24} \mathrm{H}_{27} \mathrm{~N}_{2} \mathrm{OS}^{+}$(calculated $\mathrm{m} / z$ 391.1839, error $2.0 \mathrm{ppm}$ ). Similarly to fragmentation spectra of fentanyl and fentanyl analogs with the unsubstituted phenylethylpiperidine group, two main characteristic fragments at $\mathrm{m} / \mathrm{z} 188.1439$ and at $m / z$ 105.0702 were observed in MS/MS spectrum of compound 4 (Fig. 5). The third relatively intense ion at $m / z, 110.9903\left(\mathrm{C}_{5} \mathrm{H}_{3} \mathrm{OS}^{+}\right.$thienoyl moiety) arose from the amide bond cleavage. A less intense ion at $m / z 204.0468$ was associated with the cleavage between the piperidine ring and $N$-phenyl-amide moiety. Several minor fragments were formed due subsequent bond-breaking in the piperidine ring. To verify position in which the thiophene ring is linked to carboxamide group, measurements using NMR had to be performed.

\section{NMR spectroscopy}

The NMR data for compound 4 were collected in Table 6. In the ${ }^{1} \mathrm{H}$ NMR spectrum, there were signals from thirteen aliphatic and thirteen aromatic protons. In the ${ }^{13} \mathrm{C} \mathrm{NMR}$ spectrum, there were eighteen signals, fourteen of which were assigned to proton-bearing carbon atoms of $\mathrm{CH}_{2}$ (four signals) and $\mathrm{CH}$ groups (one signal in aliphatic and nine in aromatic part of spectrum). The other four signals belonged to quaternary carbon atoms.

The aliphatic parts of ${ }^{1} \mathrm{H}$ as well as ${ }^{13} \mathrm{C}$ NMR spectra of compound $\mathbf{4}$ were very similar to analogous fragments of spectra of compounds $\mathbf{3}$ although slight differences in chemical shifts were observed. Based on the NMR data the presence of the para substituted piperidine ring and ethylene group were confirmed.

The analysis of the coupling pattern of signals of thirteen aromatic protons in the ${ }^{1} \mathrm{H}$ NMR and ${ }^{1} \mathrm{H}\left\{{ }^{1} \mathrm{H}\right\} \mathrm{COSY}$ spectra as well as the aromatic part of the ${ }^{13} \mathrm{C}$ NMR spectrum (the nine signals of $\mathrm{CH}$ group and three signals of quaternary carbon atom) confirmed the presence of two phenyl and 2-thiophene groups.

The signal of quaternary carbon atom located in ${ }^{13} \mathrm{C}$ NMR spectrum at 164.4 ppm (C22) could be attributed to the amide group. The 2-thiophene group was attached directly to carbonyl atom as evidenced by occurring a 
Table 6 Experimental 1D and 2D NMR spectroscopic data of compound 4 in $\mathrm{CD}_{3} \mathrm{OD}$

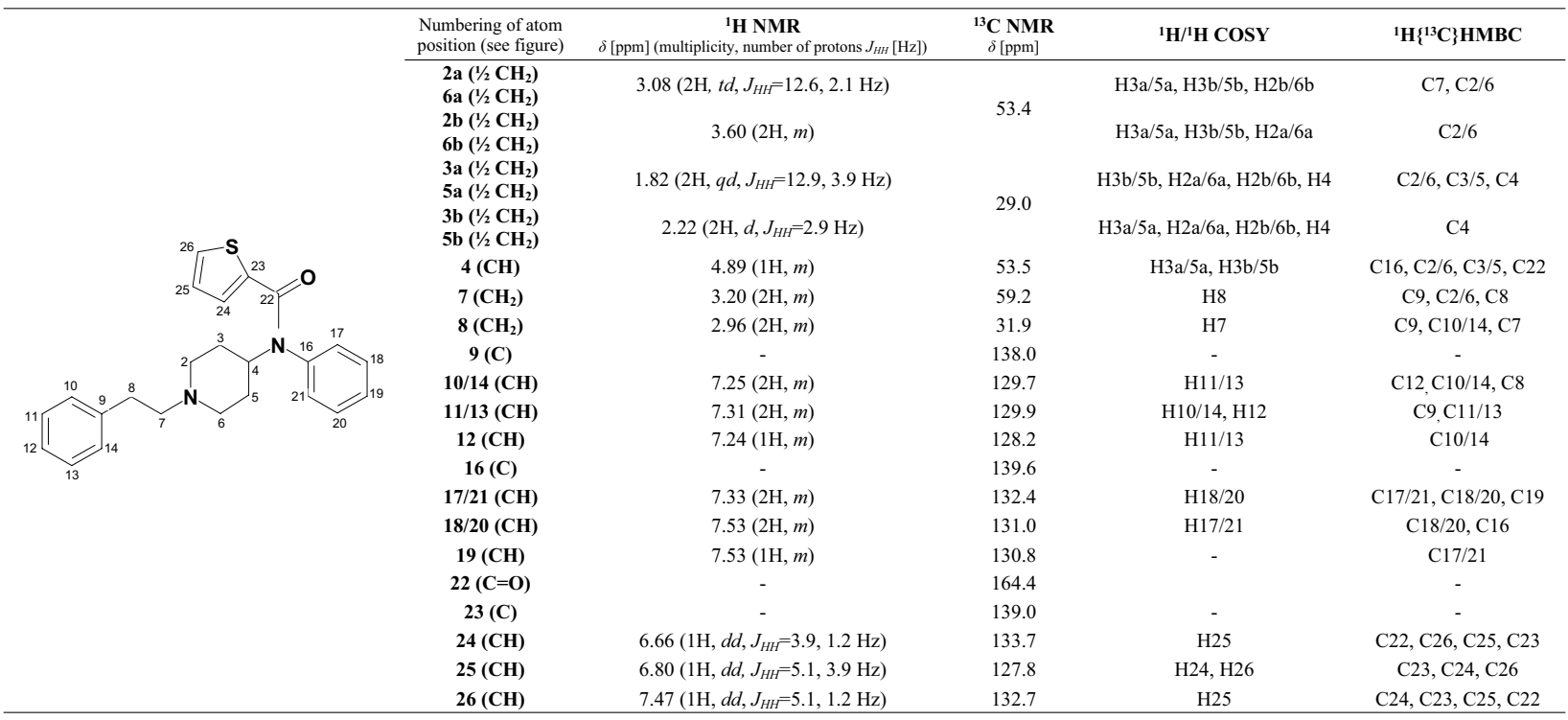

(for abbreviations, see Tables 3 and 4)

strong cross-peak in the ${ }^{1} \mathrm{H}\left\{{ }^{13} \mathrm{C}\right\}$ HMBC spectrum: $\mathrm{H} 24$ $\mathrm{C} 22$. The piperidine ring as well as phenyl group was connected to the nitrogen atom of amide group as evidenced by occurring a strong cross-peaks in the ${ }^{1} \mathrm{H}\left\{{ }^{13} \mathrm{C}\right\} \mathrm{HMBC}$ spectrum: H4-C22 and H4-C16.

Like in compounds $\mathbf{2}$ and $\mathbf{3}$, the ethylene group was connected to the other phenyl group as well as to piperidine ring via nitrogen atom.

Finally, based on mass spectra and NMR data, compound $\mathbf{4}$ was determined as $N$-phenyl- $N$-[1-(2-phenylethyl) piperidin-4-yl]thiophene-2-carboxamide, and named as 2-thiophenefentanyl. It is structurally related to furanylfentanyl. 2-Thiophenefentanyl differs from furanylfentanyl by replacement of the oxygen atom in the furan ring with a sulphur atom.

\section{Identification of compound 5: benzoylbenzylfentanyl}

\section{LC-QTOF-MS/MS results}

The protonated molecular ion at $\mathrm{m} / \mathrm{z} 371.2105$ with the predicted chemical formula $\mathrm{C}_{25} \mathrm{H}_{27} \mathrm{~N}_{2} \mathrm{O}^{+}$(error $3.4 \mathrm{ppm}$ ) was detected in LC-QTOF-MS/MS spectrum. Elimination of the benzyl moiety and the cleavage between the piperidine ring and $\mathrm{N}$-phenyl-amide moiety resulted in the formation of two most intense product ions in MS/MS spectrum at $\mathrm{m} / \mathrm{z}$ 91.0538 and 174.1281 , respectively (Fig. 6). Similarly to compound 3 a product ion at $m / z 105.0337$ which derived from benzoyl moiety elimination was present. Less intense product ions were formed by the piperidine ring degradation. An ion at $m / z, 198.0903$ was associated with the cleavage between the piperidine ring and $N$-phenyl-amide moiety. The breaking of $\mathrm{C}-\mathrm{N}$ bonds in piperidine ring and further loss of the phenyl group generated a product ion at $\mathrm{m} / \mathrm{z}$ 188.1066. Due to limited amount of sample $\mathrm{D}$, which was a mixture of several benzylfentanyl analogs and low content of investigated compound $\mathbf{5}$ in this mixture, structural confirmation by means of NMR spectroscopy was not possible.

On the basis of mass spectra, a structure of compound $\mathbf{5}$ was proposed as $N$-(1-benzylpiperidin-4-yl)- $N$-phenylbenzamide (benzoylbenzylfentanyl).

\section{Discussion}

Except for compound 3, which has been seized and detected for the first time in Sweden in March 2017 [11], all of them were identified for the first time on the illicit EU market and reported to the EWS-EMCDDA by NMI [12-15]. Such notification includes names, identifiers of the substance, sample origin (seizure by law enforcement agencies, poisonings, samples collected from NPS users or test purchases), chemical and physical properties, analytical methodologies applied for structure elucidation or harm caused by the NPS. Analytical data are also provided, because they can substitute the reference data for other laboratories (in the absence of reference standards at the time of the first detection). All these information are collected in The European Database on New Drugs (EDND). However, access to the EDND is restricted only to the members of the Network and selected members of the national early warning systems, which implies that, except this limited group of users, other European scientists as well as control laboratories or scientific communities 
Fig. 6 Product ion spectra by LC-ESI-QTOF-MS/MS for benzoylbenzylfentanyl (compound 5) with assigned fragmentation pattern; autoscaled view (upper) and zoomed view (lower)

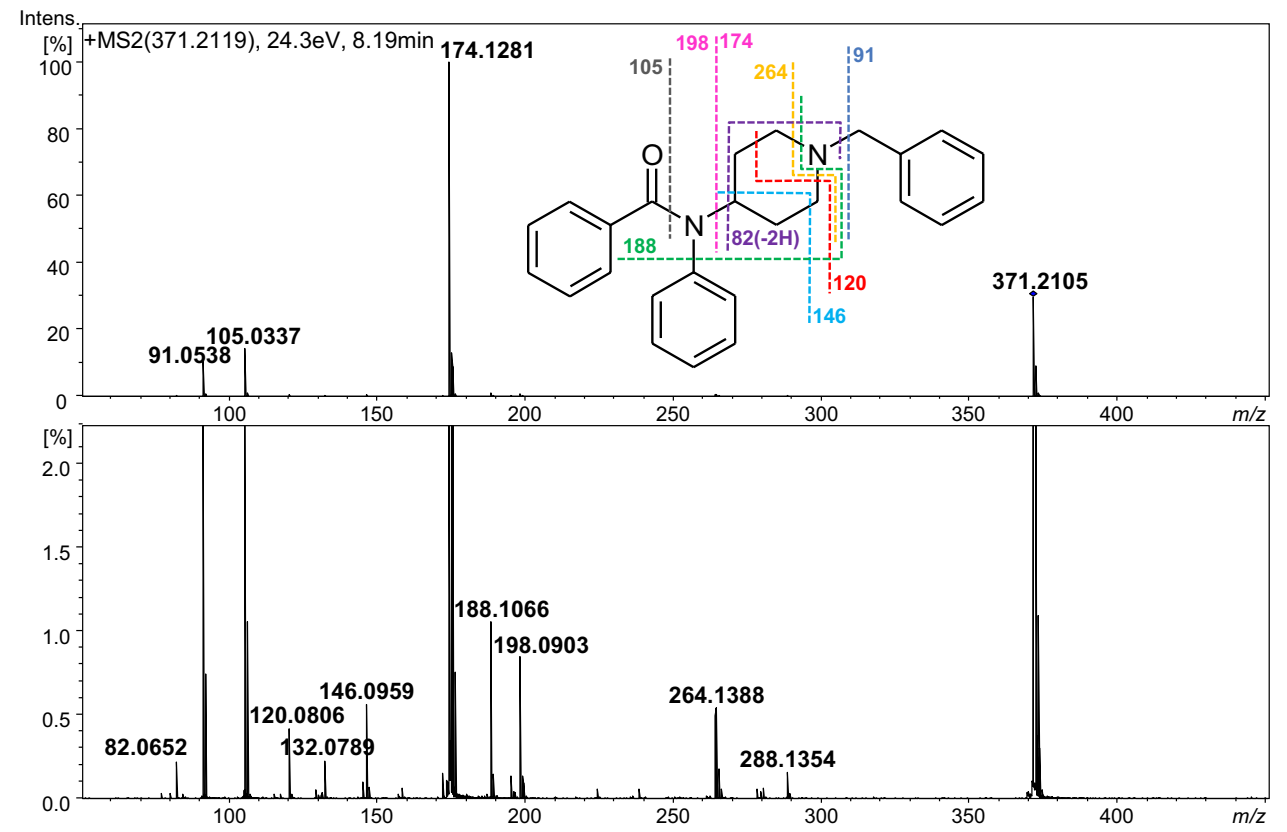

from other regions of the world cannot reach the contents of EDND system. Therefore, the publication of this manuscript in an international journal is essential to make the analytical information for these five NPS widespread in the world.

Compounds $\mathbf{1}$ and $\mathbf{2}$ have never been detected before but the structure of compound $\mathbf{2}$ was taken into account as a potential component of illicit preparation even in the 1980s [16]. After our notification, the detection of compounds 3 and $\mathbf{5}$ on the US market using gas chromatography-mass spectrometry (GC-MS) was published [17]. To the best of our knowledge, our paper is the first comprehensive report that characterized these newly identified NPSs by means of LC-QTOF-MS/MS and 1D and 2D NMR spectroscopy. Some GC-MS and ${ }^{1} \mathrm{H}$ NMR spectra without any assignments were attached to the SWGDRUG monographs [18, 19] or commercial websites providing product information of analytical reference standards [20-23]. In the case of compound 3, available literature or reports [24] contained only selected analytical information, therefore, we present complete LC-QTOF-MS/MS and NMR data for easier identification and characterization of benzoylfentanyl.

The molecule of compound $\mathbf{1}$ is structurally related to internationally controlled U-47700. Two chlorine groups at the 3- and 4-positions on the phenyl ring in U-47700 structure are replaced with a methylenedioxy group in 3,4-methylenedioxy-U-47700 molecule. The modification based on methylenedioxy group introduction to positions 3 and 4 of the aromatic ring was observed also in other NPS classes like phenylethylamines, cathinones, aminoindanes, piperazines and even synthetic opioids which belong to fentanyl analogs (benzodioxole fentanyl).

In case of compound $\mathbf{4}$, if one based the identification on LC-MS/MS results only, it should be performed with caution, because its isomer may have similar MS/MS spectrum. In this study, 2-position of thiophene moiety was verified by the NMR, however, the reference standards of 3-thiophene isomer is currently also available and potentially may appear on the illicit market.

Compound $\mathbf{5}$ differs from compound $\mathbf{3}$ by the removal of single carbon in a chain of $\mathrm{N}$-substituent of piperidine ring. According to the literature [25], such a structure modification dramatically reduces the potency of fentanyl $N$-benzyl analogs, leaving them inactive. However, Polish authorities responsible for NPS supervision, reported fatal intoxications associated with the products of the same name as sample D, in which fentanyl with benzylfentanyl were found. In sample $D$ fentanyl was not detected. Results of this sample analysis, in which four compounds including two $\mathrm{N}$-benzylfentanyl, two $N$-benzylfentanyl derivatives and 1-benzyl-4-propionyloxypiperidine were identified, indicated that it was most probably the effect of the failed synthesis. One of the major compound in sample D 1-benzyl-4-propionyloxypiperidine was reported as a manufacturing impurity and a marker of Jenssen synthesis route of illicit fentanyl [26].

\section{Conclusions}

In this study, identification and analytical characterization of five synthetic opioids, including one non-fentanyl opioid belonging to "U-compounds group" and four fentanyl analogs were presented. Structure elucidation was based on LC-QTOF-MS/MS and NMR data. These synthetic opioids were detected in samples collected in Warsaw by NMI during last two years that confirmed the trend of increasing popularity of this group of NPS in Europe. 
The data presented in this article will be useful for identifying the 5 synthetic opioids included in illicit products or human specimens.

Acknowledgements This work was supported with statutory subsidies by Polish Ministry of Science and Higher Education [project number 8.66] and Ministry of Health [grant number 147/H3/BO/2018].

\section{Compliance with ethical standards}

Conflict of interest The authors declare that they have no conflict of interest.

Ethical approval This article does not contain any studies with human participants or animals performed by any of the authors.

Open Access This article is licensed under a Creative Commons Attribution 4.0 International License, which permits use, sharing, adaptation, distribution and reproduction in any medium or format, as long as you give appropriate credit to the original author(s) and the source, provide a link to the Creative Commons licence, and indicate if changes were made. The images or other third party material in this article are included in the article's Creative Commons licence, unless indicated otherwise in a credit line to the material. If material is not included in the article's Creative Commons licence and your intended use is not permitted by statutory regulation or exceeds the permitted use, you will need to obtain permission directly from the copyright holder. To view a copy of this licence, visit http://creativecommons.org/licenses/by/4.0/.

\section{References}

1. European Monitoring Centre for Drug and Drug Addiction (2019) European drug report. Trends and development. Publications Office of the European Union, Luxembourg. https://doi. org/10.2810/191370

2. Suzuki J, El-Haddad S (2017) A review: fentanyl and non-pharmaceutical fentanyls. Drug Alcohol Depend 171:107-116. https ://doi.org/10.1016/j.drugalcdep.2016.11.033

3. Fogarty MF, Papsun DM, Logan BK (2018) Analysis of fentanyl and 18 novel fentanyl analogs and metabolites by LC-MS-MS, and report of fatalities associated with methoxyacetylfentanyl and cyclopropylfentanyl. J Anal Toxicol 42:592-604. https:// doi.org/10.1093/jat/bky035 (open access article)

4. Solimini R, Pichini S, Pacifici R, Busardò FP, Giorgetti R (2018) Pharmacotoxicology of non-fentanyl derived new synthetic opioids. Front Pharmacol 9:654. https://doi.org/10.3389/ fphar.2018.00654 (open access article)

5. Hikin L, Smith PR, Ringland E, Hudson S, Morley SR (2018) Multiple fatalities in the North of England associated with synthetic fentanyl analogue exposure: detection and quantitation a case series from early 2017 . Forensic Sci Int 282:179-183. https ://doi.org/10.1016/j.forsciint.2017.11.036

6. Armenian P, Vo KT, Barr-Walker J, Lynch KL (2018) Fentanyl, fentanyl analogs and novel synthetic opioids: a comprehensive review. Neuropharmacology 134:121-132. https://doi. org/10.1016/j.neuropharm.2017.10.016

7. Roda G, Faggiani F, Bolchi C, Pallavicini M, Dei Cas M (2019) Ten years of fentanyl-like drugs: a technical-analytical review. Anal Sci 35:479-491. https://doi.org/10.2116/analsci.18R004 (open access article)
8. de Melo Barbosa L, Santos JM, de Morais DR, Nimtz AV, Eberlin MN, de Oliveira MF, Costa JL (2019) Fast UHPLC-MS/MS method for analysis of furanylfentanyl in different seized blotter papers. Drug Test Anal 11:178-185. https://doi.org/10.1002/ dta. 2472

9. Fleming SW, Cooley JC, Johnson L, Frazee CC, Domanski K, Kleinschmidt K, Garg U (2017) Analysis of U-47700, a novel synthetic opioid, in human urine by LC-MS-MS and LC-QToF. J Anal Toxicol 41:173-180. https://doi.org/10.1093/jat/bkw131 (open access article)

10. Metushi I, Schneir A, Fitzgerald R (2017) Identification of novel synthetic opioid U-47700 through a broad screen time of flight high-resolution mass spectrometry method. Am J Clin Pathol 147(Suppl 2):S165. https://doi.org/10.1093/ajcp/aqw191.029 (meeting abstract)

11. European Monitoring Centre for Drugs and Drug Addiction (2017) Benzoylfentanyl. EU early warning system formal notification EU-EWS-RCS-FN-2017-0018

12. European Monitoring Centre for Drugs and Drug Addiction (2018) 3,4-Methylenedioxy-U-47700. EU early warning system formal notification EU-EWS-RCS-FN-2018-0021

13. European Monitoring Centre for Drugs and Drug Addiction (2018) 2-Methylacetylfentanyl. EU early warning system formal notification EU-EWS-RCS-FN-2018-0039

14. European Monitoring Centre for Drugs and Drug Addiction (2017) Thiophenefentanyl. EU early warning system formal notification EU-EWS-RCS-FN-2017-0041

15. European Monitoring Centre for Drugs and Drug Addiction (2017) Benzoylbenzylfentanyl. EU early warning system formal notification EU-EWS-RCS-FN-2017-0051

16. Moore JM, Allen AC, Cooper DA, Carr SM (1986) Determination of fentanyl and related compounds by capillary gas chromatography with electron capture detection. Anal Chem 58:1656-1660. https://doi.org/10.1021/ac00121a013

17. Casale JF, Mallette JR, Claro G, Hays PA, Frisch M, Chan KT (2018) Synthesis and characterization of benzoylfentanyl and benzoylbenzylfentanyl. Microgram J 15:1-8 (open access article)

18. SWGDRUG monograph (2018) 2-Thiophenoyl fentanyl $\mathrm{HCl}$. https://www.swgdrug.org/Monographs/2-Thiophenoyl\%20fen tanyl.pdf. Accessed 20 Feb 2019

19. SWGDRUG monograph (2017) Benzoylbenzyl fentanyl. https ://www.swgdrug.org/Monographs/Benzoylbenzyl\%20fentanyl .pdf. Accessed 20 Feb 2019

20. Cayman Chemical (2017) GCMS. https://www.caymanchem .com/gcms/22753-0511960-GCMS.pdf. Accessed 15 May 2019

21. Cayman Chemical (2017) GCMS. https://www.caymanchem .com/gcms/23548-0516520-GCMS.pdf. Accessed 15 May 2019

22. Cayman Chemical (2017) GCMS. https://www.caymanchem .com/gcms/22802-0511239-GCMS.pdf. Accessed 20 Feb 2019

23. Cayman Chemical (2018) GCMS. https://www.caymanchem .com/gcms/24249-0522385-GCMS.pdf. Accessed 20 Feb 2019

24. European Monitoring Centre for Drugs and Drug Addiction (2017) Benzoylfentanyl. Case report: EDND-CR-2019-3564

25. Vardanyan RS, Hruby VJ (2014) Fentanyl-related compounds and derivatives: current status and future prospects for pharmaceutical applications. Future Med Chem 6:385-412. https://doi. org/10.4155/fmc.13.215

26. Lurie IS, Berrier AL, Casale JF, Iio R, Bozenko JS Jr (2012) Profiling of illicit fentanyl using UHPLC-MS/MS. Forensic Sci Int 220:191-196. https://doi.org/10.1016/j.forsciint.2012.02.024

Publisher's Note Springer Nature remains neutral with regard to jurisdictional claims in published maps and institutional affiliations. 